University of South Florida

DIGITAL COMMONS

@ UNIVERSITY OF SOUTH FLORIDA
Digital Commons @ University of

South Florida

6-1-2013

\title{
Transit Boardings Estimation and Simulation Tool (TBEST) Calibration for Guideway and BRT Modes
}

CUTR

Follow this and additional works at: https://digitalcommons.usf.edu/cutr_nctr

\section{Recommended Citation}

"Transit Boardings Estimation and Simulation Tool (TBEST) Calibration for Guideway and BRT Modes," National Center for Transit Research (NCTR) Report No. CUTR-NCTR-RR-2012-02, Center for Urban Transportation Research, University of South Florida, 2013.

DOI: https://doi.org/10.5038/CUTR-NCTR-RR-2012-02

Available at: https://scholarcommons.usf.edu/cutr_nctr/102

This Technical Report is brought to you for free and open access by the National Center for Transit Research (NCTR) Archive (2000-2020) at Digital Commons @ University of South Florida. It has been accepted for inclusion in Research Reports by an authorized administrator of Digital Commons @ University of South Florida. For more information, please contact digitalcommons@usf.edu. 


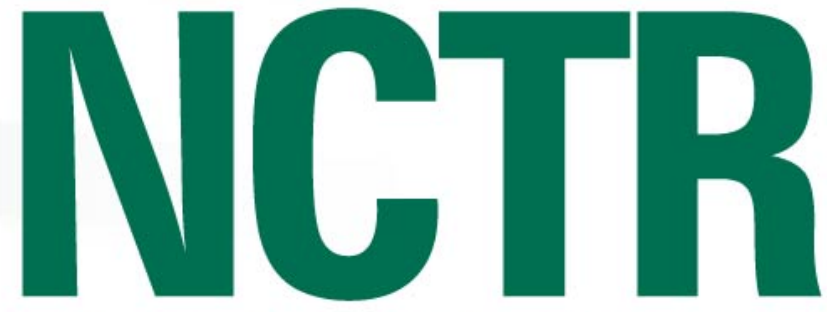

NATIONAL CENTER for TRANSIT RESEARCH

\section{Transit Boardings Estimation and Simulation Tool (TBEST) Calibration for Guideway and BRT Modes}

June 2013

PROJECT NO.

FDOT BDK85 Task Work Order \#977-40

PREPARED FOR

Florida Department of Transportation

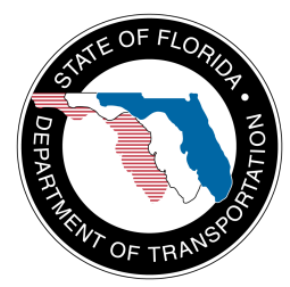




\section{Transit Boardings Estimation and Simulation Tool (TBEST) Calibration for Guideway and BRT Modes}

FDOT Project Number BDK85 977-40

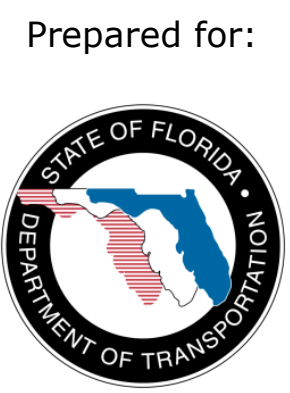

Florida Department of Transportation

Gabrielle Matthews, Project Manager

Prepared by:

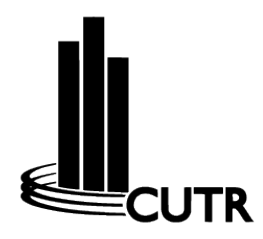

\footnotetext{
USF Center for Urban Transportation Research

Steven Polzin, Director, Mobility Policy Research

Rodney Bunner, Research Associate

Xuehao Chu, Senior Research Associate
}

Final Report

June 2013 


\section{Disclaimer}

The opinions, findings, and conclusions expressed in this publication are those of the authors and not necessarily those of the State of Florida Department of Transportation. 


\section{Metric Conversion}

\begin{tabular}{|c|c|c|c|c|}
\hline SYMBOL & WHEN YOU KNOW & MULTIPLY BY & TO FIND & SYMBOL \\
\hline \multicolumn{5}{|c|}{ LENGTH } \\
\hline in & inches & 25.4 & millimeters & $\mathrm{mm}$ \\
\hline ft & feet & 0.305 & meters & $\mathrm{m}$ \\
\hline yd & yards & 0.914 & meters & $\mathrm{m}$ \\
\hline mi & miles & 1.61 & kilometers & $\mathrm{km}$ \\
\hline \multicolumn{5}{|c|}{ VOLUME } \\
\hline fl oz & fluid ounces & 29.57 & milliliters & $\mathrm{mL}$ \\
\hline gal & gallons & 3.785 & liters & L \\
\hline $\mathrm{ft}^{3}$ & cubic feet & 0.028 & cubic meters & $\mathrm{m}^{3}$ \\
\hline$y d^{3}$ & cubic yards & 0.765 & cubic meters & $\mathrm{m}^{3}$ \\
\hline \multicolumn{5}{|c|}{ NOTE: volumes greater than $1000 \mathrm{~L}$ shall be shown in $\mathrm{m}^{3}$} \\
\hline \multicolumn{5}{|c|}{ MASS } \\
\hline $\mathbf{o z}$ & ounces & 28.35 & grams & $g$ \\
\hline lb & pounds & 0.454 & kilograms & $\mathrm{kg}$ \\
\hline $\mathbf{T}$ & short tons $(2000 \mathrm{lb})$ & 0.907 & $\begin{array}{c}\text { megagrams } \\
\text { (or "metric ton") }\end{array}$ & $\mathrm{Mg}$ (or "t") \\
\hline \multicolumn{5}{|c|}{ TEMPERATURE (exact degrees) } \\
\hline${ }^{\circ} \mathbf{F}$ & Fahrenheit & $\begin{array}{c}5(F-32) / 9 \\
\text { or }(F-32) / 1.8\end{array}$ & Celsius & ${ }^{\circ} \mathrm{C}$ \\
\hline
\end{tabular}




\section{Technical Report Documentation}

\begin{tabular}{|c|c|c|c|}
\hline $\begin{array}{l}\text { 1. Report No. } \\
\text { BDK85 977-40 }\end{array}$ & 2. Government Acce & sion No. & 3. Recipient's Catalog No. \\
\hline $\begin{array}{l}\text { 4. Title and Subtitle } \\
\text { Transit Boardings Estim } \\
\text { Calibration for Guidewa }\end{array}$ & $\begin{array}{l}\text { and Simulation Tool (TBEST } \\
\text { BRT Modes }\end{array}$ & $\begin{array}{l}\text { 5. Report } \\
\text { June } 20\end{array}$ & \\
\hline 6. Performing Organizatior & & & \\
\hline $\begin{array}{l}\text { 7. Author(s) } \\
\text { Steven Polzin, Ph.D.; R } \\
\text { Ph.D. }\end{array}$ & Bunner; Xuehao Chu, & $\begin{array}{l}\text { 8. Performing Or } \\
\text { NCTR 77945/B } \\
\text { U.S.DOT DTRS }\end{array}$ & $\begin{array}{l}\text { zation Report No. } \\
5977-40 \\
5-0032\end{array}$ \\
\hline $\begin{array}{l}\text { 9. Performing Organizatior } \\
\text { National Center for Trar } \\
\text { Center for Urban Trans } \\
\text { University of South Flor } \\
4202 \text { East Fowler Aven }\end{array}$ & $\begin{array}{l}\text { e and Address } \\
\text { esearch } \\
\text { tion Research } \\
\text { JT100, Tampa, FL } 33620\end{array}$ & 10. Work Unit Nc & RAIS) \\
\hline $\begin{array}{l}\text { 11. Contract or Grant No. } \\
\text { BDK85 } 977-40\end{array}$ & & & \\
\hline $\begin{array}{l}\text { 12. Sponsoring Agency Na } \\
\text { Research and Innovativ } \\
\text { U.S. Department of Tra } \\
1200 \text { New Jersey Ave., } \\
20590 \\
\text { Florida Department of } 7 \\
605 \text { Suwannee Street, }\end{array}$ & $\begin{array}{l}\text { dd Address } \\
\text { chnology Administration, } \\
\text { tation, Mail Code RDT-30 } \\
\text { oom E33, Washington, DC } \\
\text { portation, Research Center } \\
\text { D, Tallahassee, FL } 32399\end{array}$ & $\begin{array}{l}\text { 13. Type of Repo } \\
\text { Final Report } \\
\text { January 2012- }\end{array}$ & $\begin{array}{l}\text { id Period Covered } \\
2013\end{array}$ \\
\hline 14. Sponsoring Agency Co & & & \\
\hline $\begin{array}{l}\text { 15. Supplementary Notes } \\
\text { Supported by a grant fr } \\
\text { Transportation }\end{array}$ & e Florida Department of Tra & Dortation and t & S. Department of \\
\hline $\begin{array}{l}\text { 16. Abstract } \\
\text { This research initiative } \\
\text { Transit Boardings Estim } \\
\text { the planning communit } \\
\text { rapid transit (BRT) tech } \\
\text { and LRT calibration. Th } \\
\text { features and scaling the } \\
\text { adjustment factor woul } \\
\text { travelway along the full }\end{array}$ & $\begin{array}{l}\text { notivated by a desire of the } \\
\text { and Simulation Tool (TBEST } \\
\text { mproving its capability to prc } \\
\text { jies. Specific strategies for ca } \\
\text { methodology relied on a sco } \\
\text { rship impact accordingly, bas } \\
\text { a maximum of } 30 \text { percent for } \\
\text { th. }\end{array}$ & $\begin{array}{l}\text { orida Departmer } \\
\text { project team to } \\
\text { ide forecasts for } \\
\text { bration were ex } \\
\text { ing system to de } \\
\text { d on the best av } \\
\text { very highly spe }\end{array}$ & $\begin{array}{l}\text { Transportation and the } \\
\text { ance the value of TBEST to } \\
\text { t rail transit (LRT) and bus } \\
\text { ed and developed for BRT } \\
\text { nine the scope of BRT } \\
\text { ble empirical data. The BRT } \\
\text { ed BRT with exclusive }\end{array}$ \\
\hline $\begin{array}{l}\text { The LRT strategy relied } \\
\text { regional model forecast } \\
\text { changes and competitiv } \\
\text { necessary to replicate } L \\
\text { a forthcoming Federal } T \\
\text { technology adjustments }\end{array}$ & $\begin{array}{l}\text { mparison of TBEST results } \\
\text { Hillsborough County. These } \\
\text { of rail was such that large } \\
\text { recasts. In light of these res } \\
\text { Administration sketch planr } \\
\text { more than } 50 \text { percent. }\end{array}$ & $\begin{array}{l}\text { th both sketch p } \\
\text { sults suggested } \\
\text { justments in TB } \\
\text { ts, the project te } \\
\text { ng model and, ir }\end{array}$ & $\begin{array}{l}\text { ing LRT forecasts and } \\
\text { the scope of system } \\
\text { forecasts would be } \\
\text { suggests recalibration with } \\
\text { interim, restricting }\end{array}$ \\
\hline $\begin{array}{l}\text { 17. Key Words } \\
\text { TBEST, transit ridership } \\
\text { light rail transit }\end{array}$ & casting, bus rapid transit, & $\begin{array}{l}\text { 18. Distribution } \\
\text { Available to the } \\
\text { Technical Inform } \\
\text { Royal Road, Spri } \\
\text { http://www.ntis. } \\
\text { at http://www.nch }\end{array}$ & $\begin{array}{l}\text { ment } \\
\text { c through the National } \\
\text { iservice (NTIS), } 5285 \text { Port } \\
\text { ld, VA 22161, (703) } 487-4650 \text {, } \\
\text { and through the NCTR website } \\
\text { sf.edu/ }\end{array}$ \\
\hline $\begin{array}{l}\text { 19. Security Classification } \\
\text { (of this report) } \\
\text { Unclassified }\end{array}$ & $\begin{array}{l}\text { 20. Security Classification } \\
\text { (of this page) } \\
\text { Unclassified }\end{array}$ & $\begin{array}{l}\text { 21. No. of Pages } \\
52\end{array}$ & \begin{tabular}{l|l} 
22. Price \\
\end{tabular} \\
\hline
\end{tabular}




\section{Acknowledgments}

Appreciation is given to Ken Cervenka of the Federal Transit Administration (FTA), who provided information on federal processes for sketch planning for LRT/BRT. Thanks also to researchers from the National Bus Rapid Transit Institute at the USF Center for Urban Transportation Research, who provided resource documents and information on BRT performance. 


\section{Executive Summary}

\section{Context}

This research initiative was motivated by a desire of the Florida Department of Transportation (FDOT) and the Transit Boardings Estimation and Simulation Tool (TBEST) project team to enhance the value of TBEST to the planning community by improving its capability to provide forecasts for light rail transit (LRT) and bus rapid transit (BRT) technologies. Specifically, this research was intended to investigate how best to add these forecasting capabilities to TBEST in a manner that acknowledges their distinctive features that have been shown to have differential appeal to travelers relative to traditional fixedroute bus services.

This project was sponsored by the FDOT Office of Public Transportation and carried out under the auspices of the National Center for Transit Research (NCTR) at the University of South Florida's Center for Urban Transportation Research (CUTR). This effort builds on a history of investment by FDOT in enhancing planning tools to support public transportation planners and operators in Florida. Multiple prior studies contributed to the development and enhancement of TBEST and its deployment in Florida.

The growing interest in enhanced public transportation service, specifically BRT, but also LRT, created a desire to conduct research regarding how best to model BRT ridership within the context of the TBEST model and databases. Ideally, this would involve calibrating model equations to reflect measured experience of these technologies in attracting travel demand. However, the scarcity of such systems in Florida and the lack of robust before-and-after data for existing BRT services resulted in the need to adapt a variety of strategies to produce LRT and BRT modeling capability in TBEST.

This new capability will give greater confidence to users for the application of TBEST in sketch planning or service planning for these modes. Such a planning tool increases the capabilities of transit agencies for planning future transit services. In addition, the variability of specifications for BRT systems has resulted in the development of a specific methodology to modify BRT demand forecasts to reflect the variety of BRT features prescribed for any given BRT system. The capability also allows for treatment of LRT lines in the context of TBEST applications in urban areas. As transit services are integrated between technologies, it is important that TBEST be able to accommodate LRT as part of an integrated multitechnology transit.

This report is intended to document the activities carried out in accomplishing this research and provide the reader with an understanding of the logic and strategy used to integrate these features in TBEST. Perhaps more relevant to planners, this effort resulted in numerous changes to the TBEST software package associated with the integration of these forecasting capabilities in the prior version of TBEST. Documentation of these changes in terms of user manual modifications is integrated as part of the ongoing effort to keep usersupport materials updated. This report does not replicate those materials. Updated guidance 
on how to use TBEST with LRT and BRT forecasting capabilities can be found at the TBEST website at http://tbest.org/.

\section{Strategy}

In exploring strategies for how to treat BRT in the context of the TBEST modeling, several considerations came into play:

1. TBEST is designed principally for Florida application; however, the model variables and the transit service area calibration strategy integrated in TBEST provide greater model transferability than is the case for many traditional public transit forecasting models. This means that the strategy for validating the model is dependent on data available from Florida transit operations, which, currently, do not include LRT or BRT services for which stop-level ridership data are available.

2. Both technologies, but particularly BRT, are relatively diverse in terms of their features and performance, making it less likely to expect a single technology variable (BRT, for example) whose characteristics vary dramatically from slightly dressed-up bus services to highly-distinctive dedicated guideway services similar to LRT on rubber tires.

3. Even when considering experiences across the country, high-quality, stop-level data on BRT ridership relative to traditional bus services are nonexistent at the quality level that might be desired for rigorous statistical coefficient development. BRT features are very different in different systems, and their impact on ridership is often confounded by other context changes, such as gas price changes, background bus service network changes, fare changes, and economic condition changes, which collectively preclude being able to attribute ridership difference before and after BRT implementation solely to the difference between traditional bus and BRT services.

4. The impact of BRT designation of service on ridership may not be stable over time, as the perception of BRT-one of the factors that can impact its relative appeal to prospective passengers-is likely to continue to evolve as more systems are implemented and operated across the country. A number of factors may play into this issue, including the novelty effect or "coolness" or "progressiveness" that passengers might attribute to these services. The diversity of systems being implemented, and depending upon whether or not these systems maintain their quality of service and facilities over time, might ultimately impact their appeal to passengers. Similarly, as some elements of BRT systems, such as automated fare collection and high-quality customer information, make their way into all bus service operations, the distinctiveness of BRT compared to traditional bus service may be dampened.

The fundamental motivation for this research is the evidence that some of the ridership difference across modal technologies cannot be explained solely by traditional quantitative characteristics such as speed, frequency, span of service, and cost. The logical argument is that the physical presence of the system, its image, and perhaps its reliability and ride quality result in higher technology modes that attract more riders than would be explained solely by the speed, frequency, span, or other technical traits that can be easily modeled. 
This issue has long been recognized within the transit modeling community and can be more easily dealt with for LRT modes due to less variation in features across the projects. Within BRT, both greater variation and less post-implementation data are available for modeling.

In light of this situation, the adopted logic envisions separating out features whose impacts are partially or wholly captured by standard service variables from those whose impacts are perception- or service-quality-related. The project team used a type of scaling factor in which ridership adjustment would be incremented for BRT relative to bus service based on the elements that are shown to enhance perception and/or service quality. Such a contextsensitive structure is likely to be more flexible in accommodating the variation in projects but also more reliant on fitting and judgment, as opposed to traditional rigorous data-driven statistical calibration.

Review of the literature and the state of the practice indicated a number of conditions that drive the logic structure of this initiative. BRT is an evolving technology with a wide variety of project specifications, resulting in very different experiences for passengers and different costs for project development. This has led to a flexible structure to accommodate contextspecific BRT characteristics in model development. These features and the sub-elements are:

- $\quad$ BRT Vehicle

- Floor height

- Articulated bus

- Aerodynamics/aesthetics

- Alternative fuel

- Guided/steering technology

- $\quad$ BRT Station

- Physical presence/architecture

- Shelter

- Real-time information

- Fare vending

- Off-vehicle fare collection

- Travel Way

- Exclusivity

- Signal preemption/priority

- Visual distinctiveness of travel way

- Branding/Marketing

For purposes of incorporating the impact of these various characteristics on ridership, they are attributed to three factors-image, physical presence, and customer service. Each of these factors is more easily relatable to ridership consequence. Based on a scoring system, the planner characterizes the planned BRT systems against these traits, and a composite score is developed that represents the basis for modifying ridership relative to base bus 
service with the same model input characteristics (socio-demographic information, quality of service information, etc.) to account for what would be considered intangible or indirect impacts on ridership that are not captured in model coefficients. This score is then synchronized against the best available data that report the ridership of BRT relative to preexisting base bus service.

In many ways, the challenges of expanding TBEST to have an LRT forecasting capability are similar to the situation for BRT described above. LRT is a decades-old technology but still suffers from modest data on deployed systems due to the relatively limited number of LRT systems in the U.S. (fewer than two dozen, depending on how streetcar and legacy systems are counted). Regarding LRT forecasting, standard industry practice is to build local transit forecasting models with guideway sensitivity based on local calibration where possible. In the absence of local systems, coefficients are borrowed or transferred from similar contexts where available. There is also a high degree of variance regarding LRT specifications in terms of performance characteristics and physical presence. As was the case with BRT, there are no LRT systems operating in Florida.

In light of the absence of actual Florida experience for calibration, a variety of other possible strategies for determining a model/adjustment process that realistically represents LRT in TBEST were explored. The project team considered the possibility of using other documented LRT forecasting methods to produce an LRT forecast that could then be used as "actual" ridership for purposes of subsequent TBEST LRT calibration. While somewhat unorthodox, this method has the virtue of enabling the production of an LRT forecast that uses validated composite behaviors regarding LRT drawn from a host of LRT applications.

Four LRT sketch planning type tools were considered as a basis for defining LRT ridership for purposes of calibration to TBEST:

1. Existing Federal Transit Administration (FTA) LRT sketch planning tool

2. Regional model forecasts

3. Sketch planning tool developed as part of TCRP Project H-42, "An Exploration of Fixed Guideway Transit Criteria Revisited"

4. New FTA model known as STOPS (Simplified Trips-on-Project Software), expected to be available when the final New Starts and Small Starts Policy Guidance is available later in 2013

Due to schedule constraints and with the concurrence of FDOT, Options 3 and 4 were eliminated because they were not publicly available for application at the time of this publication. Option 2, using regional model forecasts as "actual" ridership to which TBEST would be calibrated, was a possibility; however, forecasts that reflect current transit service and conditions are not available for the recommended application site in Florida (Hillsborough County) nor for other Florida locations. Thus, the project team used the existing FTA sketch planning tool to develop a ridership forecast for the LRT/BRT corridor in Hillsborough County and used this as the "actual" LRT ridership for purposes of TBEST calibration. 


\section{Findings}

Synthesizing the information gleaned from reviewing a variety of BRT studies and the transit industry understanding of elasticities of demand (ridership) with respect to various transit system characteristics, as documented in TCRP Report 95, "Traveler Response to Transportation System Changes," judgments were made regarding a determination of the extent to which observed BRT ridership increases could be apportioned between known changes in transit variables, such as travel speed and service supply, that impact ridership and those that could not be accounted for by performance characteristics already captured in the specification of service. Based on this review, as well as focusing on relatively highly prescribed BRT systems (systems that offer a full range of enhancements such as exclusive right-of-way, level boarding, off-vehicle fare vending, distinct stations, etc.) such as those for which the maximum technology factor adjustments would be received (Kansas City Max line, Eugene, Oregon EmX line, and Cleveland HealthLine were highly-prescribed systems with the most information available) and accounting to the extent possible for impacts of service and speed, data indicated an approximately 25 to 30 percent greater ridership than would be the case for identical service having none of the BRT characteristics. Accordingly, the TBEST model BRT adjustment factor used the scaling approach referenced above and provides a maximum 30 percent ridership adjustment associated with a perfect score or full menu of BRT features deployed throughout the BRT line.

The suggested initial 30 percent ridership adjustment for highly-prescribed BRTs is a number that can be reviewed and updated over time as new data are collected regarding the performance of BRT systems being deployed across the country.

For the LRT analysis, results using the Aggregate Rail Ridership Forecasting (ARRF) model were calculated for two corridors in Tampa. The adjustment factors necessary to convert TBEST numbers to replicate ARRF forecasts are both large and very significantly different between the two alignments.

Based on these results, the project team compared the results to the ridership forecasts carried out as part of the Hillsborough County Alternative Analysis for the North-South corridor in Hillsborough County. These forecasts also suggested an approximate doubling of ridership for the rail alignments compared to similar levels of bus service.

The project team found the variation beyond the range of credibility of technology adjustment factors observed in travel forecasting. A number of factors could be at play here. In light of these variances, the project team reflected on the potential reasons for the variation and concluded that part of the variation is a result of the timeframes for forecasting, where LRT forecasts are typically for a $20+$ year time horizon and may be operating in a situation where the relative competitive comparison of travel preference between roadway and transit travel has changed. Typically, LRT systems have significant park-and-ride components of ridership that are not currently well-handled within the TBEST framework. In addition, LRT systems typically result in a rather dramatic reconfiguration of bus services within a broadly-defined corridor of implementation with the intention of directing a great deal of the overall system demand on to the LRT alignment. In the test 
application case, several parallel high-performing bus routes continue to exist in the TBEST simulation. In reality, more dramatic service reconfiguration might be anticipated with LRT implementation and would serve to boost ridership onto the LRT.

In light of these findings, it is recommended that the LRT adjustment factor be set no greater than 50 percent and be redesignated after completion of the FTA STOPS model. The modified TBEST framework and the incorporation of an adjustment factor for LRTs within that framework will enable these changes to be made expeditiously. Additionally, further testing, perhaps against LRT proposals in Florida, such as those in Pinellas and Broward Counties, might provide additional opportunities to explore TBEST LRT forecasting capabilities with more robust feeder service specification and the availability of regional model ridership forecast results. 


\section{Table of Contents}

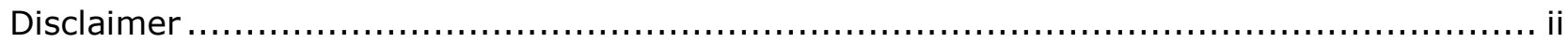

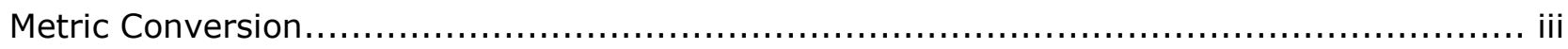

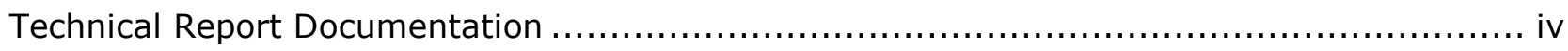

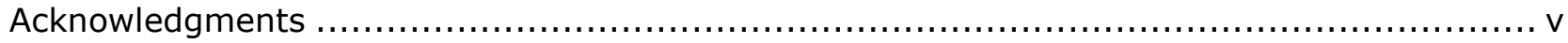

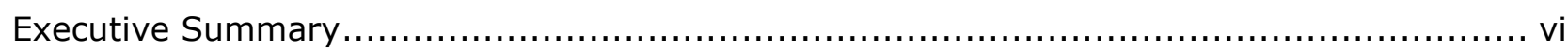

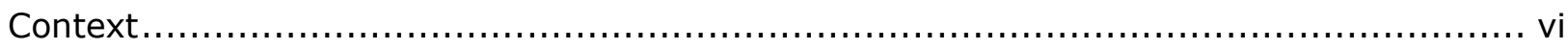

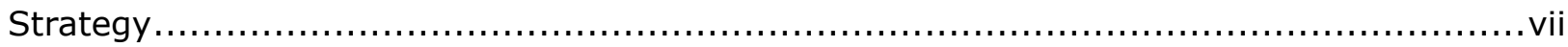

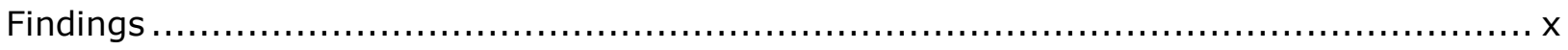

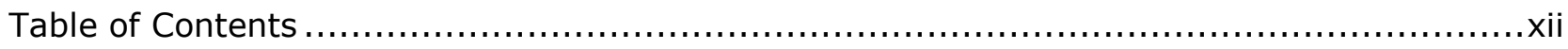

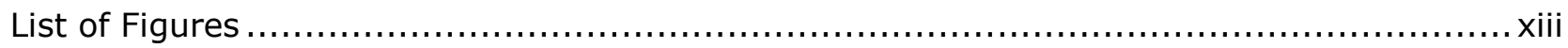

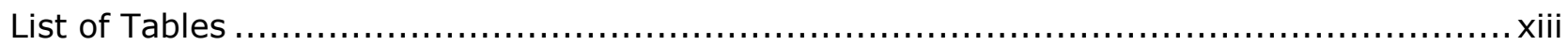

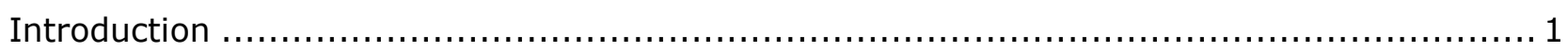

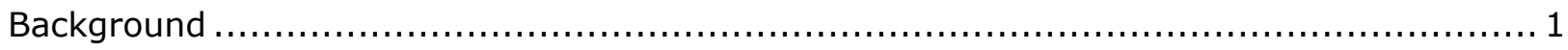

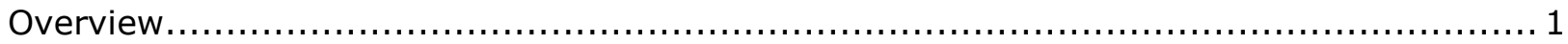

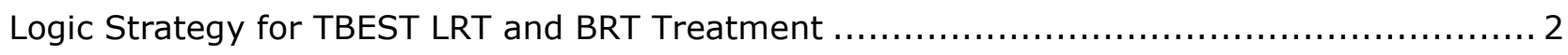

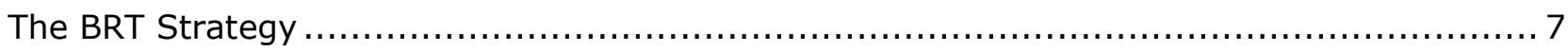

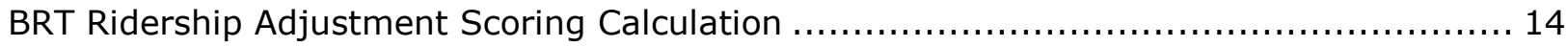

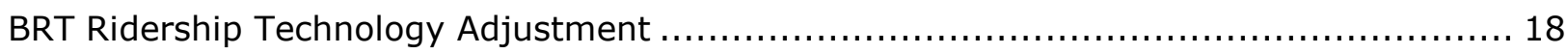

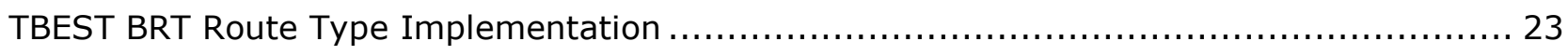

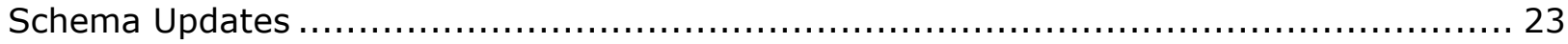

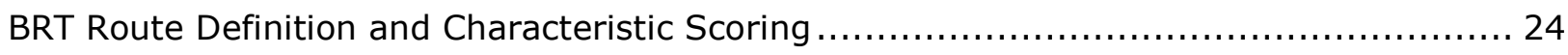

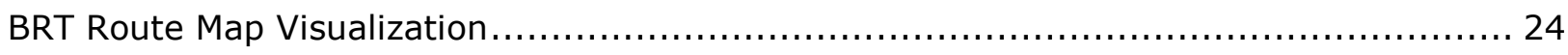

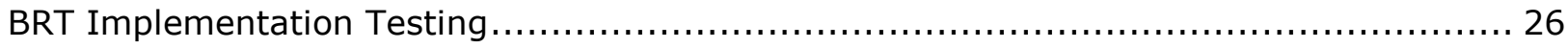

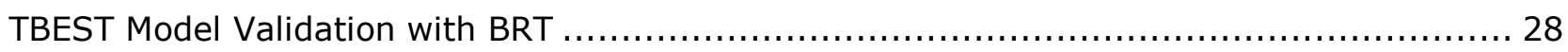

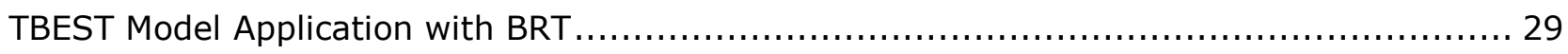

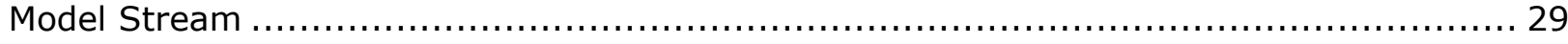

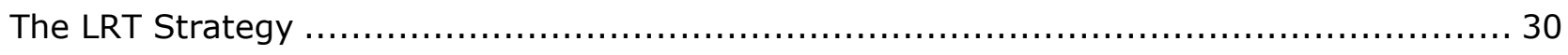

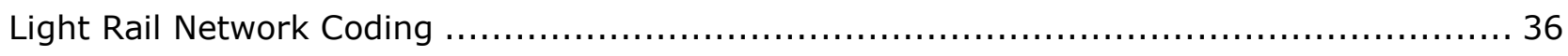

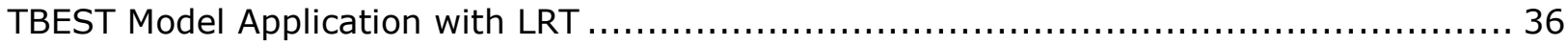

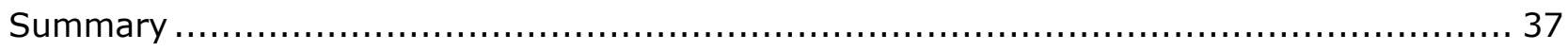

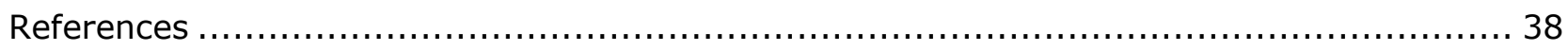




\section{List of Figures}

Figure 1 BRT Route Characteristics Definition Form ................................................................ 8

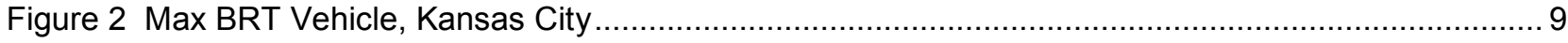

Figure 3 HealthLine Articulated Bus, Cleveland .................................................................... 9

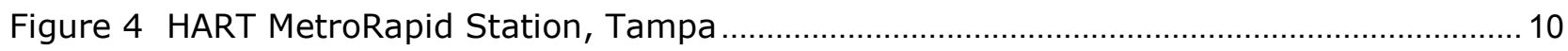

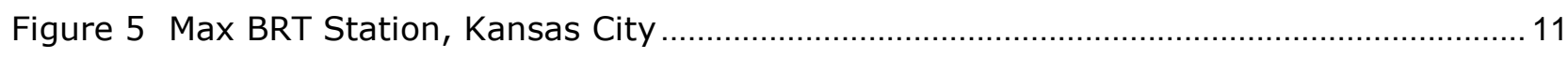

Figure 6 HealthLine Raised-Platform Median Station, Cleveland ............................................ 11

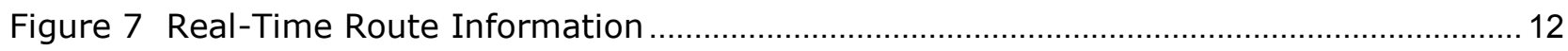

Figure 8 HealthLine Exclusivity Travel Way, Cleveland ............................................................. 12

Figure 9 SilverLine Station and Travel Way, Boston............................................................ 13

Figure 10 BRT Ridership Adjustment Scoring Strategy ........................................................... 15

Figure 11 BRT Ridership Adjustment Scoring Strategy, HART MetroRapid ............................... 16

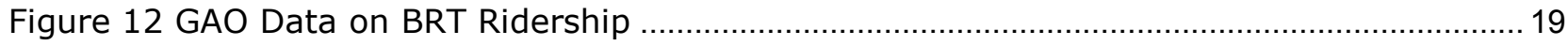

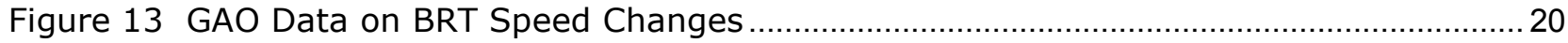

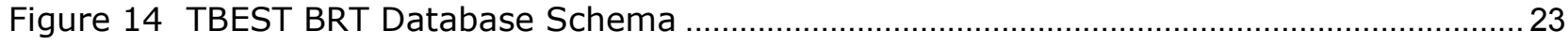

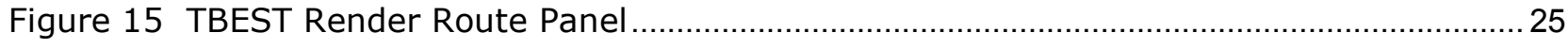

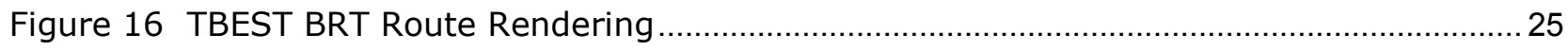

Figure 17 HART MetroRapid BRT Route Characteristics Definition................................................26

Figure 18 Screen Capture of ARRF Spreadsheet of HART BRT Route ......................................... 32

Figure 19 TBEST New Route Dialog for LRT Designation ............................................................. 36

\section{List of Tables}

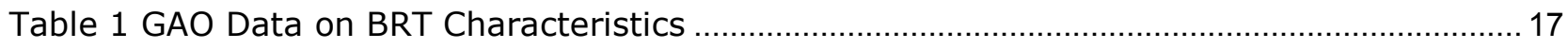

Table 2 TBEST LRT Calibration via TBEST Bus/ARRF Comparisons............................................. 35 


\section{Introduction}

\section{Background}

This research initiative was motivated by a desire of the Florida Department of Transportation (FDOT) and the Transit Boardings Estimation and Simulation Tool (TBEST) project team to enhance the value of TBEST to the planning community by improving its capability to provide forecasts for light rail transit (LRT) and bus rapid transit (BRT) technologies. Specifically, this research was intended to investigate how best to add these forecasting capabilities to TBEST in a manner that acknowledges the distinctive features of LRT and BRT that have differential appeal to travelers relative to traditional fixed-route bus services. Ideally, this would involve calibrating model equations to reflect measured experience of these technologies in attracting travel demand. However, the scarcity of such systems in Florida and the lack of robust before-and-after data for existing BRT services resulted in the need to adapt a variety of strategies to produce LRT and BRT modeling capability in TBEST.

This new capability will give greater confidence to users in the application of TBEST in sketch planning or service planning for these modes. Such a planning tool increases the capabilities of transit agencies for planning future transit services. In addition, BRT demand forecasting tools must be altered to reflect the variety of featues for any given BRT system.

Transit agencies across Florida will be able to use such a capability. It will be most relevant to mid-size and larger agencies, many of which are exploring BRT or guideway investments. As modified, TBEST allows analysis of integrated multi-technology transit systems.

\section{Overview}

This report is intended to document the activities carried out in accomplishing this research and provide the reader with an understanding of the logic and strategy used to integrate these features in TBEST. Perhaps more relevant to planners, this effort resulted in numerous changes to the TBEST software package associated with the integration of these forecasting capabilities in the prior version of TBEST. Documentation of these changes in terms of user manual modifications is produced as part of the ongoing effort to keep usersupport materials updated. This report does not replicate those materials. Updated guidance on how to use TBEST with LRT and BRT forecasting capabilities will be posted to the TBEST website at http://tbest.org/. 


\section{Logic Strategy for TBEST LRT and BRT Treatment}

TBEST, as previously designed, had a set of transit demand model coefficients calibrated for traditional fixed-route bus transit travel. TBEST is a direct demand model in which four major considerations collectively provide the basis for estimating the transit demand generated at any given transit stop:

1. Socio-demographic characteristics of the population around the stop

2. Activity levels of the land-use around the stop

3. Access to the transit stop

4. Access to other destinations via the transit network

This model, while best used as a tool for estimating route segment- and route-level ridership, is built with the geographic specificity sensitive to the geography of a transit stop. As the majority of transit travelers access transit service via walking, the geographic scale relevant to walking trip decision-making is the basis for defining the geographic scale of TBEST data. The pre-existing model had the capability and supporting data to accommodate public transit networks with varying types of routes. These route types (local, express, radial, circulator) would each have their own local calibration factor to reflect the fact that different route types tend to perform differently relative to the four major determinants of demand, but such applications required the presence of existing ridership data for each route type as a basis for defining differential ridership propensity across route types. In addition, there was no capability within TBEST to differentiate by technology features such as bus services with off-vehicle fare payment, level boarding or station next-arrival information signage. Thus, the model was not helpful for testing new service concepts in areas that did not currently have those service concepts in operation, and it did not have a level of flexibility one might desire to accommodate the diverse set of characteristics that might describe a given BRT or LRT plan. Even in an area with an existing BRT system, the model would not provide a flexible means of estimating ridership for an additional BRT system whose characteristics might be quite different than the existing BRT.

Within the planning and modeling community, there have long been discussions regarding how best to estimate ridership for technologies that might be different than existing technologies and whose characteristics might induce different travel behavior responses from potential passengers that go beyond the characteristics that have historically been integrated into forecasting model equations. For example, mode choice models have historically accommodated key features such as cost, speed, and accessibility within the modeling framework. However, numerous other traits, such as travel time reliability, comfort/ride quality, and awareness/image, are among the characteristics of transit mode technologies that are not necessarily among the variables in models but are known to affect demand. Most often, these characteristics are difficult to quantify and

Research suggests that at least some... choice riders would be unwilling to ride a traditional bus, but will ride BRT.

CALSTART, "Bus Rapid Transit

Ridership Analysis," FTA (June 2005) 
not wholly known to planners; they are traditionally not introduced into demand models in the form of technology variables. Rather, mode choice models are calibrated for specific technologies such that the variable coefficients for model constants capture the differential attractiveness of a different technology. Depending upon the modeling structure, these adjustment factors for technology constants account for different travel demand propensity associated with different modes. Historic research has confirmed that guideway systems and higher levels of technology have a different appeal to travelers that can result in greater use for services that otherwise might be identical to traditional bus services.

In exploring strategies for how to treat BRT in the context of the TBEST modeling process, several considerations came into play:

- This is a model designed principally for Florida application; however, the model variables and the transit service area calibration strategy integrated in TBEST provide greater model transferability than is the case for many traditional public transit forecasting models. This means that the strategy for validating the model is dependent on data available from Florida transit operations, which currently do not include LRT or BRT services where stop-level ridership data are available.

- Both technologies, but particularly BRT, are relatively diverse in terms of their features and performance, making it less likely to expect a single technology variable to be the most appropriate strategy to accommodate what might be different appeals across the range of facilities/services that are commonly characterized as LRT or BRT. This is particularly true for BRT systems that are still in their formative years and whose characteristics vary dramatically from slightly dressed-up bus services to highly-distinctive dedicated guideway services similar to LRT on rubber tires.

- Even when considering experiences across the country, high-quality, stop-level data on BRT ridership relative to traditional bus services are non-existent at the quality level that might be desired for rigorous statistical coefficient development. BRT features are very different in different systems, and their impact on ridership is often confounded by other context changes such as gas price changes, background bus service network changes, fare changes, and economic condition changes that collectively preclude being able to attribute ridership difference before and after BRT implementation solely to the difference between traditional bus and BRT services.

- The impact of BRT designation of service on ridership may not be stable over time, as the perception of BRT-one of the factors that can impact its relative appeal to prospective passengers-is likely to continue to evolve as more systems are implemented and operated across the country. A number of factors may play into this issue, including the novelty effect or "coolness" or "progressiveness" that passengers might attribute to these services. With the diversity of systems being implemented, and depending upon whether or not these systems maintain their quality of service and facilities over time, it might ultimately impact their appeal to passengers. Similarly, as some of the elements of BRT systems such as automated fare collection and high-quality customer information make their way into all bus 
service operations, the relative distinctiveness of BRT compared to traditional bus service may be dampened.

The collective impact of these factors influenced the ultimate strategy adopted for integrating BRT and LRT forecasting capabilities into the TBEST model. These conditions suggested a flexible strategy that could accommodate various different definitions of BRT and also suggested a model framework whereby the differential ridership appeal of BRT can be, in effect, updated as more empirical evidence is accumulated over time regarding the impact of BRT on ridership, specifically in Florida applications.

An additional qualifier for LRT and BRT modeling relates to the treatment of park-and-ride travel demand. The TBEST modeling structure does include designation of the stop as a park-and-ride location, and this variable does impact ridership based on the model's influence of park-and-ride on ridership, as reflected by calibration data from Florida transit properties. However, park-and-ride transit operations in Florida are not particularly mature and are characterized as having relatively modest park-and-ride facilities and modest levels of service. Part of this situation is attributable to the fact that park-and-ride is most successful in applications where services target very high-density, large concentrations of employment in large central business districts with relatively high auto parking costs that attract long-distance white-collar commuters from distant middle-income suburban communities.

As these situations are relatively infrequent in Florida, they are not incorporated within the park-and-ride sensitivity of the TBEST model. LRT and BRT services, as premium services and often with longer-distance routes, are more likely to have park-and-ride access than traditional non-express bus services. The limited sensitivity of demand forecasting models, including TBEST, to the presence of park-and-ride in Florida might not fully account for park-and-ride demand should stronger park-and-ride markets materialize over time. This need to enhance park-and-ride transit demand forecasting for Florida forecasting within (or independent of) the TBEST modeling framework has been acknowledged in the TBEST strategic plan.

One other dimension of calibration in the context of TBEST is presented before discussing the specific strategy for this project. TBEST is somewhat distinct as a model, in that it is intended to be transferable between urban area locations without extensive recalibration of the basic model coefficients. What this means is that the project team believes that the explanatory factors influencing transit ridership-access to the mode, accessibility via the mode, and quality of service as influenced by frequency, span, fare-are fundamental factors that are consistent across geography. However, it is acknowledged that transit use does vary across urban areas even if one corrects for social demographic and service characteristics. There appears to be both an urban scale effect (areas with more extensive transit systems enable more activities to be reached via transit, making it inherently more attractive, even if the relative attractiveness between transit and alternative means of travel remains constant) and perhaps a cultural effect or other effects that cannot be explained by socio-demographic or service characteristics but that does result in different levels of transit use in areas that otherwise might seem similar. 
In addition, it is acknowledged that certain characteristics of the transit system, such as perceptions of its safety, "coolness" or acceptability, cleanliness, customer friendliness, etc., can have an impact on ridership across geographies and yet are not service characteristics that have been integrated into demand forecasts. In light of this, the TBEST model application process for a given geography involves "calibrating" the model to local conditions by running a base forecast and then calculating an urban location adjustment factor that modifies the base forecast ridership to match actual ridership in the base year.

This process of setting up a model for a given urban area is intended to "fit" the
One of the key features of LRT or BRT that makes them attractive is the transit agency's commitment to quality service, including more frequent service and expanded hours of operation. Similarly, many LRT and BRT features are designed to increase the operating speed of service. These characteristics are captured within the existing TBEST model logic structure and model coefficients. It is important to remember that the additional technology adjustment to ridership propensity alluded to in these discussions is intended that capture other inducements to increase ridership beyond those already captured within the logic structure and variables used in the TBEST model. model to the local behavior by adjusting for any cultural, service quality, or urban scale factors that might result in ridership levels different than those one would get based on unadjusted application of the forecasting equation coefficients. This calibrating step is applied by service type and, thus, should provide an initial model appropriate for subsequent application in the particular urban area. Given this feature, TBEST can accommodate any mode or technology within its existing framework if that technology currently exists in the urban area such that a service type or technology adjustment factor can be calculated.

Part of the motivation for exploring treatment of BRT and LRT modeling is the fact that these technologies are not currently available in Florida urban areas to form the basis for an initial TBEST calibration. Accordingly, the methodology discussed in the remainder of this report is most relevant in applications where planners desire to conduct ridership forecasts for technologies that do not currently exist in the referenced urban area. Thus, the proposed strategies are intended for use in markets that are exploring the introduction of these technologies.

Over time, based on Florida-specific experience for both LRT and BRT, there may be a basis for further modification of TBEST forecasting methodologies for these technologies. In the case of BRT, there may be feedback within the next several years as to the success of BRT applications in Florida relative to previous traditional bus service ridership and perhaps relative to forecasts made with TBEST and/or other forecasting tools. In the case of LRT, timeframes for implementation are such that we are, in all probability, more than a decade away from having actual ridership to compare against planning estimates. However, over time, we may learn more about ridership forecasting for both of these modes and can be in a stronger position to modify model adjustments, as appropriate, to best reflect the 
changing state of the practice and empirical experience with ridership forecasting for BRT and LRT. In each subsequent section of this report, there is discussion regarding conditions under which future modifications may be appropriate.

In light of the discussion above, the strategy for calibrating both BRT and LRT are discussed in the following sections sequentially. 


\section{The BRT Strategy}

BRT calibration issues were discussed in the project kickoff meeting and in subsequent team discussions. As there are no BRT systems operating in Florida that provide a strong calibration environment, Hillsborough County was used as the target location for calibration. The team's working knowledge of the area aided in understanding model behavior at the stop level.

The growing body of experience with BRT is gravitating toward a greater appreciation of the variance of BRT characteristics across projects. Terminology such as Metro Rapid, BRT light, and Full BRT speak to the variation in cost and features across applications. This is compounded by the fact that features can change along the alignment (particularly the extent of exclusivity of right-of-way). The fundamental motivation for this research is the evidence that some of the ridership difference across modal technologies cannot be explained solely by traditional quantitative characteristics such as speed, frequency, span of service, and cost. The logical arguments are that the physical presence of the system, its image, and perhaps its reliability and ride quality result in higher technology modes that attract more riders than would be explained solely by the speed, frequency, span or other technical traits that can be easily modeled. This issue has long been recognized within the transit modeling community and can be more easily dealt with for LRT modes due to less variation in features across projects. Within BRT, there are both greater variation and less post-implementation data available for modeling. Some of the classification strategies for defining BRT are using an inventory or counting of features as a determinant of type of BRT. These strategies count features such as passenger stations, boarding height, off-board fare payment, distinctive vehicles, real-time or other passenger information systems, exclusive right-of-way, preferential signal treatment, and others.

In light of this situation, the adopted logic envisions separating out features whose impacts are partially or wholly captured by standard service variables from those whose impacts are perception or service quality related. The project team decided to use a type of scaling factor in which ridership adjustment would be incremented for BRT relative to bus service based on the elements that are shown to enhance perception and/or service quality. Such a context-sensitive structure is likely to be more flexible in accommodating the variation in projects but also more reliant on fitting and judgment as opposed to traditional rigorous data-driven statistical calibration.

Review of both the literature and the state of the practice indicated those conditions that are driving the logic structure of this initiative. BRT is an evolving technology with a wide variety of project specifications, resulting in very different experiences for passengers and different costs for project development. This has led to a flexible structure to accommodate context-specific BRT characteristics in model development.

Figure 1 characterizes the BRT features that are specified as part of a method for determining the ridership benefits of BRT implementation. This figure is a screen capture of an input screen in TBEST. Each feature is discussed below. 
Figure 1 BRT Route Characteristics Definition Form

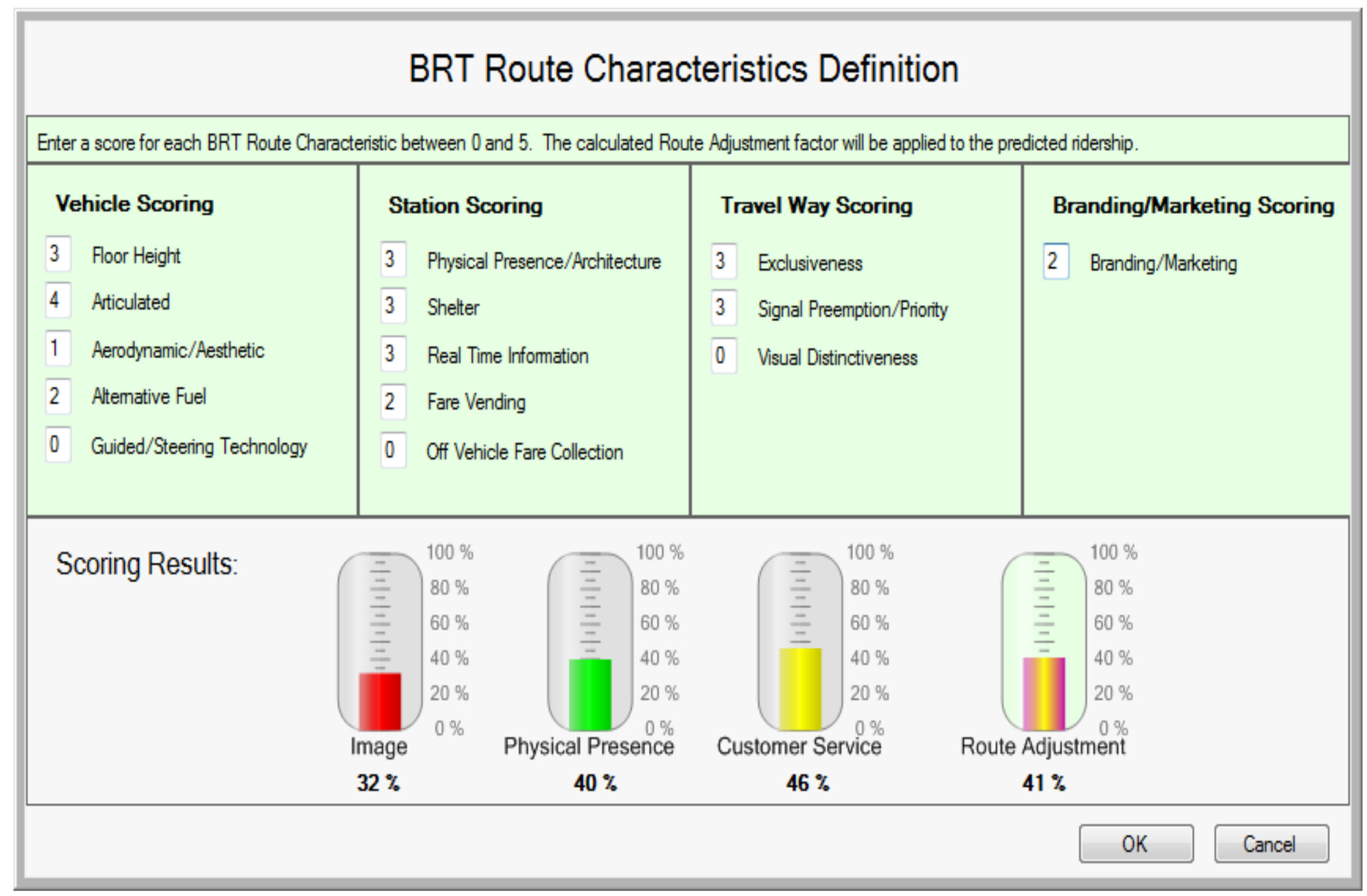




\section{BRT Vehicle}

One of the principal elements that can differentiate a BRT system from traditional bus service is the vehicle. There are several vehicle characteristics that create the overall image and perception of the vehicle and influence customers perceptions as well as the convenience and comfort of the vehicle. Figures 2 and 3 show examples of BRT vehicles.

\section{Floor Height}

Figure 2 Max BRT Vehicle, Kansas City

Floor heightspecifically, the difference in height between the bus station and the vehicle floor-is a factor influencing convenience and comfort levels as well as dwell time for the vehicle. A low-floor vehicle or high platform station makes the vehicle more attractive and comfortable for passenger boarding and alighting. This can be accomplished through a combination of low-floor vehicles and boarding platforms to minimize the difference between station and vehicle heights. Level boardings across the system would be assigned a score of 5 on a 0-5 scale for floor height. If there were no differences between

Figure 3 HealthLine Articulated Bus, Cleveland

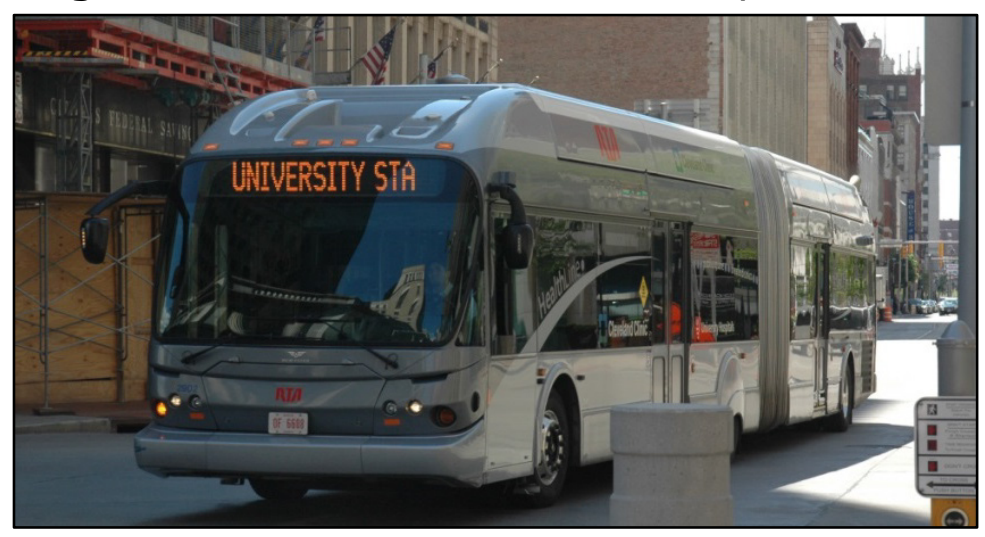
station and vehicle floors relative to traditional bus service, this factor would be assigned a score of 0 . For situations where there was a mix of vehicles and station platforms such that boarding locations offered enhanced conditions or where the floor height differences were less than in traditional vehicles, the assigned score for floor height would vary between 1 and 4 based on the judgment of the analyst. One way to think about this would be to base the scaling on the percentage of stations and the percentage of change in the height difference between platform and vehicle floor relative to standard bus services.

\section{Articulated Bus}

Articulated vehicles are larger and have a more significant physical presence and more train-like appearance. They accommodate larger crowds and often have additional doors to enhance boarding convenience. The articulated bus factor is scored proportionally to the percentage of articulated buses in the BRT fleet, with a maximum score of 5 . 


\section{Aerodynamics/Aesthetics}

Aerodynamics/Aesthetics refers to the visual image that the vehicle creates relative to traditional buses. Agencies use a host of methods to change vehicle image, ranging from different color schemes and vehicle labeling to various types of body claddings and design elements that can significantly influence the visual appeal and distinctiveness of the vehicle relative to traditional buses. Distinctive vehicles with a modern appearance, such as the Civis (French-designed, highly-stylized, articulated, vehicle guidance equipped) bus, would be assigned a score of 5 in this category. Vehicles that were identical with the exception of paint schemes would be assigned a score of 1 . Interior features such as carpeting, added seating, digital displays, cameras, automatic stop enunciation, and other distinctive features might be considered for higher scoring in this category.

\section{Alternative Fuel}

The use of alternative fuel or an alternative powertrain for a vehicle can offer a variety of benefits, including lessened pollution, better mileage, lower noise levels, and a distinctively different image to the public. Alternatively-fueled/powered vehicles create the impression of a progressive, environmentally sensitive agency. A fully electric or hydrogen fuel-cell coach, for example, might be assigned a score of 5 in this category. A diesel hybrid coach might be assigned a score of 3 , and a compressed natural gas (CNG) coach might be assigned a score of 2 or 3 , depending upon whether or not it was present only in the BRT line.

\section{Guided/Steering Technology}

If a vehicle incorporated additional technologies to help steer or guide it or to enhance its precision docking at stations or otherwise minimize right-of-way requirements, it might be assigned a score of 5 in this category. Absent any special treatment, it would be assigned a score of 0 .

\section{BRT Station}

The second major element of BRT that differentiates it from traditional bus service is the presence of stations rather than bus stops. Figures 4 through 6 show examples of BRT stations. These stations represent more significant infrastructure investment and offer both amenities for passengers and a physical presence that advertises the service. Stations create a sense of permanence, Figure 4 HART MetroRapid Station, Tampa symbolizing to both customers and the broader community that the service is a serious commitment to the specific location. At a practical level, the station can provide amenities, 
such as shelter from inclement weather, customer information, fare vending, seating, lighting, etc., that serve to make the wait for service more comfortable. Characteristics of stations that help define their potential impact are described in the following paragraphs.

\section{Physical Presence/Architecture}

The extent of infrastructureboth its size and its physical presence and appealsymbolize to passengers and the community something about the transit service. An attractive and visually identifiable station signals the presence of the service in the community. Travelers passing through the area would be able to connect that facility with the presence of quality transit service and would be more likely to have a sense of where that service goes within the community based on their awareness of these distinct stations. A station with a significant physical presence that would be easily noticed and positively regarded by passengers and other potential customers would be assigned a score of 5 . More modest facilities would have lower scores reaching 0 if the stop/shelters were comparable to the norm in that community for other transit routes.

\section{Shelter}

The quality of the shelter, while related to the physical presence, reflects the comfort and security levels that a customer would perceive in using the facilities. Sun and rain protection, wind protection, heating in cold climates, lighting, and visibility from the travel way would be among the amenities that would offer benefits to passengers. A well-sheltered location would be assigned a score of 4 or 5 , and an exposed shelter whose primary 
purpose was physical presence, not passenger protection, would be assigned a score of 1 or 2 .

Figure 7 Real-Time Route Information

\section{Real-Time Information}

This refers to the presence of real-time electronic information at the station that tells passengers when service is expected (Figure 7). The presence of information on the BRT route might be assigned a score of 4 , with 5 assigned in situations in which connecting service information is also available. The absence of information would result in a score of 0 . Interim score levels might apply to situations where real-time information is available at some stations but not all.

\section{Fare Vending}

The presence of kiosks or other means of selling fare media at the station (versus on the vehicle) would be assigned a score of 5 if available throughout the system. Lower scores would apply depending on the extent of coverage of fare vending services and system stations.

\section{Off-Vehicle Fare Collection}

The extent to which the system has an honor fare system or other off-vehicle fare collection strategy that would decrease dwell times and increase customer convenience could result in a score of 5. Partial deployment would reduce the score if traditional on-vehicle fare collection were used throughout the BRT line.

\section{Travel Way}

A key factor in BRT success and perception is the extent to which the travel way provides both higher-quality service to customers and a strong physical presence to the broader community.

Figure 8 HealthLine Exclusivity Travel Way, Cleveland

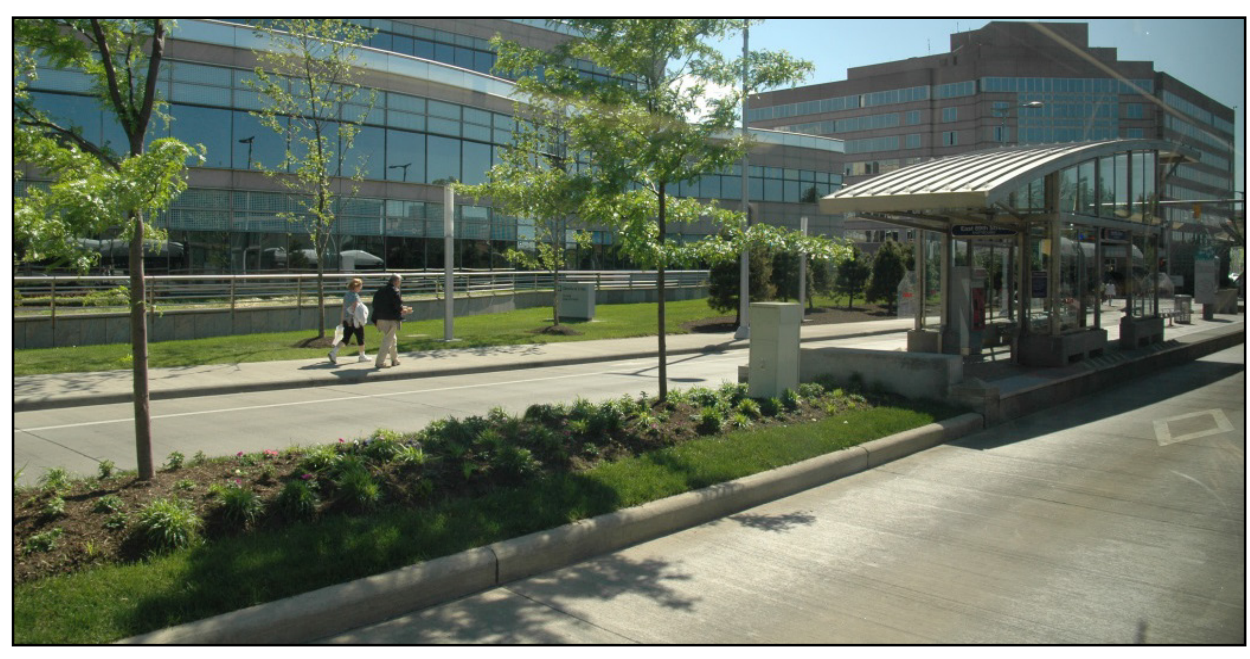

Figures 8 and 9 are examples of BRT travel ways.

\section{Exclusivity}

The ultimate high-quality travel way would be an exclusive travel way for BRT services. A BRT system operating on exclusive travel way throughout its length would be assigned a 
score of 5. Lower scores would be received based on the proportion of exclusive right-ofway offered. Shared lane use with the presence of queue jumps at a number of intersections might result in the score of 1 .

\section{Signal Preemption/ Priority}

Another common BRT feature to provide enhanced productivity and improved service for travelers is signal preemption or prioritystrategies that enable transit vehicles to travel faster due to the presence of technology that minimizes the signal delay for transit vehicles. Extensive deployment of these features that produced travel time savings would result in a score of 5 . More modest levels of deployment across the route and/or less evidence of actual

Figure 9 SilverLine Station and Travel Way, Boston

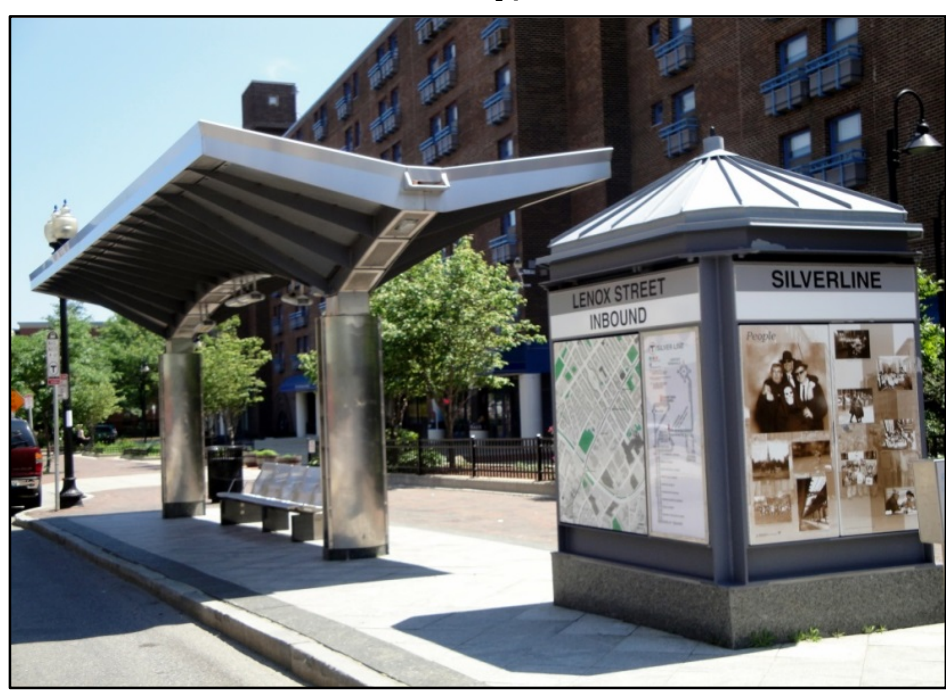
operating time savings would result in lower scores.

\section{Visual Distinctiveness of Travel Way}

The extent to which a travel way has identifiable visual characteristics signals a stronger presence to the community and travelers and can enhance safety and operating speed. This physical presence might include colored pavements, curbing, markings, or other surface treatments and also might include the presence of bus bays or pullout at stations. This distinctiveness symbolizes a commitment to quality service and increases awareness of other travelers (auto, bike, pedestrian) who might be more sensitive to impeding BRT travel.

\section{Branding/Marketing}

The success of a BRT system will be influenced by the reception the community gives to the implementation and subsequent execution of BRT services. Targeted marketing reinforcement of the distinctiveness and quality of service will influence individuals by making them aware and have positive perceptions of the service and by creating a sense of excitement and attractiveness in the corridor as a place to live, work, and conduct commerce. Ultimately, this will sustain and enhance demand over time. Simple things such as branding of the line in a manner analogous to rail lines-e.g., red line, blue line, green line-and distinguishing the lines from bus routes on maps and information pieces helps create that image and perception. Other treatments-for example, complementary planning efforts in the corridor, complete streets treatment, access management activities, zoning or land-use changes, or designation of special districts-might further enhance the awareness of the service and the distinctive market it might support. High-profile systems with distinctive badging and branding and aggressive promotion and complementary initiatives 
would be assigned a score of 5, with scores reduced proportionately, reaching 0 if the route were indistinguishable from traditional bus services beyond the route name.

\section{BRT Ridership Adjustment Scoring Calculation}

Figure 10 is a spreadsheet that lists the various characteristics and provides a scoring system to aggregate scores into a single factor that is used in the ridership adjustment process. It is acknowledged that this strategy is based on expert judgments and not on analytical methods of data clustering or statistical analysis. The data to support a more rigorous methodology are not available at this time.

To incorporate the impact of these various characteristics on ridership, they are attributed to three factors-image, physical presence, and customer service. Each of these factors is more easily relatable to ridership. A composite score is then derived based on the combination of the category factor, the score assigned by the analyst, and recommended score allocation factors. The total for each category of characteristics is the sum across the different characteristics within this category for Factor Allocation, and it is a fraction of the sum for Calculated Score. The fraction for each category of characteristics is determined by the number of characteristics in this category and the Category Factor. For example, the Vehicle category has five characteristics; hence, its fraction is $(500 \times 15 \%) /(5 \times 5 \times 100)=$ $3 \%$. These fractions are independent of specific applications.

It should be pointed out that the different characteristics in the same category are equally important in this scoring method. This composite score-whose maximum value is 500 points-will be the basis for modifying ridership relative to base bus service with the same model input characteristics (socio-demographic information, quality of service information, etc.) to account for what would be considered intangible or indirect impacts on ridership that are not captured in model coefficients and cannot be integrated into model coefficients in the absence of far more robust data that could serve as a basis for calibration across the variety of BRT trait scenarios.

Figure 11 shows the adjustment scoring factors used for the test model application in the case of the Hillsborough Area Regional Transit (HART). As the bottom right-hand corner cell indicates, the composite BRT effect adjustment factor for the HART BRT project would be 20 percent. This is 20 percent of the maximum BRT adjustment factor that would be possible for the most highly-specified BRT system. The discussion in the following section provides the basis for determining the maximum adjustment factor relative to base bus service that would occur for a premium BRT application.

Table 1 presents a self-classification of BRT characteristics for a sample of BRT projects surveyed by GAO. This exemplifies the variation in features across projects. ${ }^{1}$

\footnotetext{
${ }^{1} \mathrm{GAO}$, Report to the Committee on Banking, Housing, and Urban Affairs, U.S. Senate, "Bus Rapid Transit Projects Improve Transit Service And Can Contribute To Economic Development," GAO-12-811, July 2012.
} 
Figure 10 BRT Ridership Adjustment Scoring Strategy

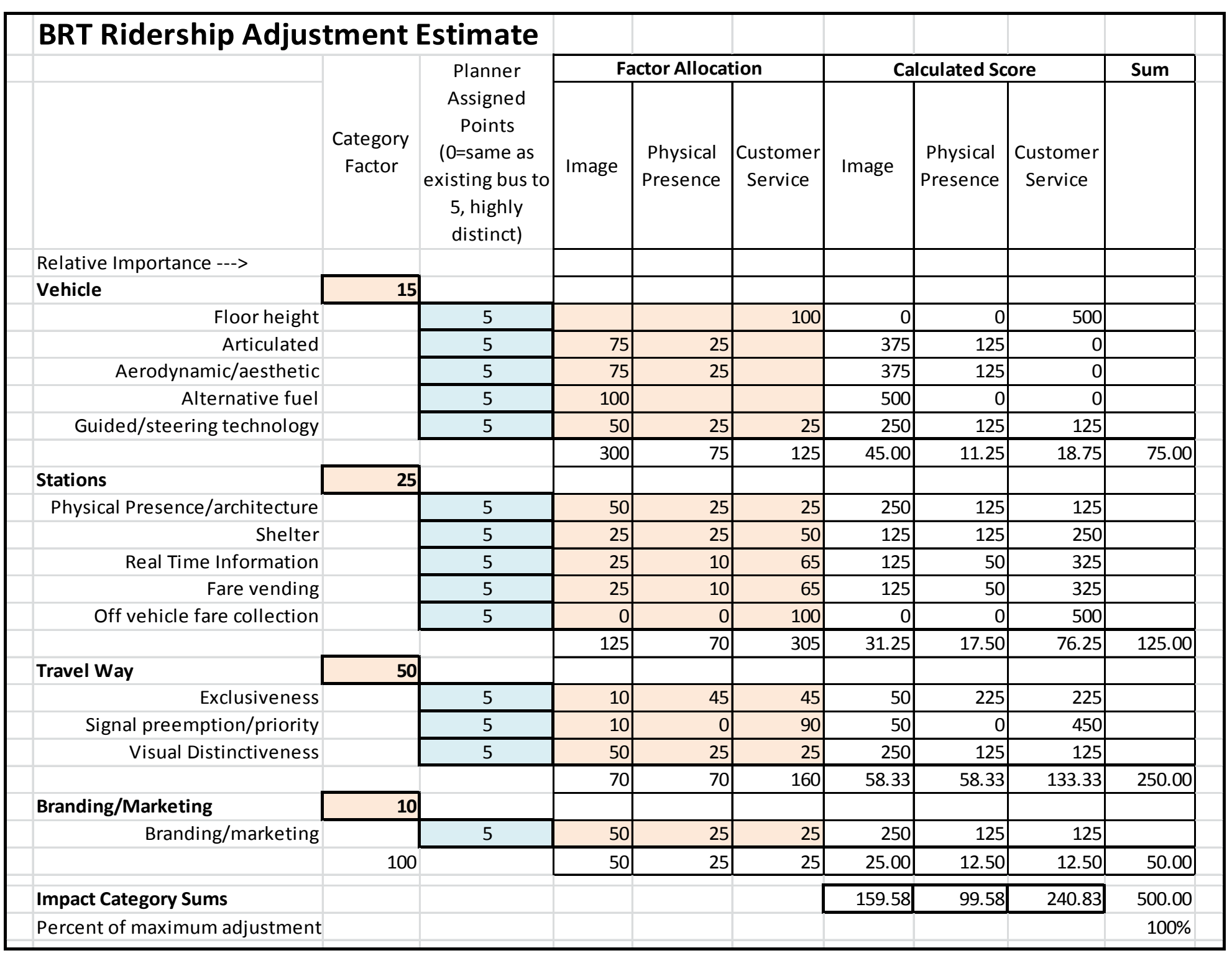


Figure 11 BRT Ridership Adjustment Scoring Strategy, HART MetroRapid

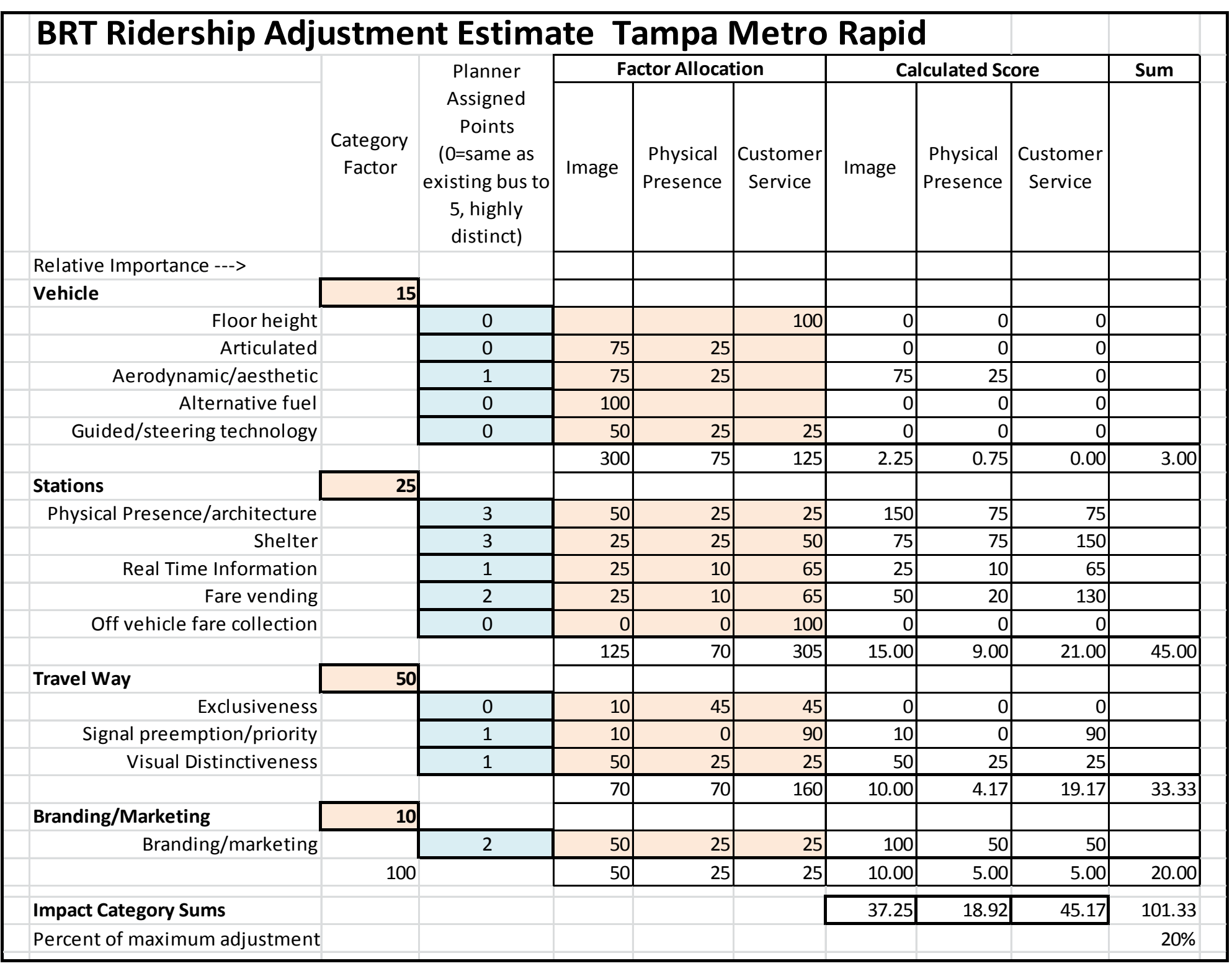


Table 1 GAO Data on BRT Characteristics

\begin{tabular}{|c|c|c|c|c|c|c|c|c|}
\hline \multirow[t]{2}{*}{ Project (Location) } & \multicolumn{2}{|c|}{$\begin{array}{c}\text { Running Ways (at least } \\
30 \% \text { of route length) }\end{array}$} & \multicolumn{2}{|c|}{$\begin{array}{c}\text { Station } \\
\text { Amenities (by } \\
\text { number of } \\
\text { amenities) }\end{array}$} & \multirow{2}{*}{$\begin{array}{c}\begin{array}{c}\text { Fare } \\
\text { Collection }\end{array} \\
\text { (Off-Board) }\end{array}$} & \multirow{2}{*}{$\begin{array}{c}\text { Vehicle } \\
\text { Features } \\
\text { (at least } 5 \\
\text { of } 11 \\
\text { features) }\end{array}$} & \multirow[t]{2}{*}{$\begin{array}{c}\text { Branding } \\
\text { and } \\
\text { Marketing }\end{array}$} & \multirow[t]{2}{*}{$\begin{array}{c}\text { ITS Features } \\
\text { (at least } 3 \text { of } \\
6 \text { features) }\end{array}$} \\
\hline & Dedicated & $\begin{array}{c}\text { Semi- } \\
\text { Dedicated }\end{array}$ & $4-6$ & $7-12$ & & & & \\
\hline Healthline (Cleveland) & $\mathrm{y}$ & & & $\mathrm{y}$ & $\mathrm{y}$ & $\mathrm{y}$ & $\mathrm{y}$ & $\mathrm{y}$ \\
\hline Franklin EmX (Eugene OR) & $\mathrm{y}$ & & & $\mathrm{y}$ & $\mathrm{y}$ & $\mathrm{y}$ & $\mathrm{y}$ & $\mathrm{y}$ \\
\hline Gateway EmX (Eugene OR) & y & $\mathrm{y}$ & & y & $\mathrm{y}$ & $\mathrm{y}$ & y & y \\
\hline RapidRide A (Seattle) & & y & $\mathrm{y}$ & & & $\mathrm{y}$ & $\mathrm{y}$ & \\
\hline M15 (New York NY) & & $\mathrm{y}$ & & & & $\mathrm{y}$ & $\mathrm{y}$ & \\
\hline RTC Rapid (Reno NV) & & & & y & y & y & y & y \\
\hline BusPlus (Albany NY) & & & y & & $\mathrm{y}$ & $\mathrm{y}$ & $\mathrm{y}$ & $\mathrm{y}$ \\
\hline $\begin{array}{l}\text { Metro Express } 44 \text { (San Joaquin } \\
\text { CA) }\end{array}$ & & & y & & y & y & y & y \\
\hline $\begin{array}{l}\text { Boulder Hwy Express (BHX) } \\
\text { (Southern NV) }\end{array}$ & & & y & & y & y & y & \\
\hline Troost MAX (Kansas City MO) & & & $\mathrm{y}$ & & & $\mathrm{y}$ & y & $\mathrm{y}$ \\
\hline The Rapid (Livermore CA) & & & y & & & $\mathrm{y}$ & $\mathrm{y}$ & $\mathrm{y}$ \\
\hline RapidRide B (Seattle) & & & $\mathrm{y}$ & & & $\mathrm{y}$ & $y$ & \\
\hline Mountain Links (Northern AZ) & & & $\mathrm{y}$ & & & $\mathrm{y}$ & y & \\
\hline $\begin{array}{l}\text { Metro Rapid Gap Closure (Los } \\
\text { Angeles) }\end{array}$ & & & & & & y & y & y \\
\hline Metro Rapid 741 (Los Angeles) & & & & & & $\mathrm{y}$ & $\mathrm{y}$ & \\
\hline Total (out of 20) & 3 & 3 & 8 & 4 & 7 & 20 & 20 & 9 \\
\hline
\end{tabular}

Note: The groupings of project sponsor data displayed in the table (i.e., $30 \%$ or more dedicated to running way, 4-6 amenities) are for illustrative purposes only and not meant to reflect critical numbers or percentages in BRT project design.

Source: GAO Analysis of project sponsor's questionnaire data. "Bus Rapid Transit Projects Improve Transit Service and Can Contribute to Economic Development," GAO-12-811, July 2012, Table 1. 


\section{BRT Ridership Technology Adjustment}

The above-referenced adjustment methodology for BRT ridership forecasts has to be anchored to the best available real world data that indicates additional ridership that might occur on a service beyond that which can be explained by other factors already incorporated in model coefficients and input data sets (population and employment/land-use changes, speed changes, fare changes, travel time changes, service span, frequency, etc.).

In determining the appropriate adjustment, a number of professionals involved in BRT projects were approached, and the collective experience of the faculty of the National Bus Rapid Transit Institute (NBRTI) was consulted.

The best resource summarizing ridership data for BRT projects was found to be a GAO report from July 2012. ${ }^{3}$ Again, it is important to note that ridership data for BRT projects virtually never contains good beforeand-after data once the system reconfiguration is accounted for, and other changes in service levels or other service features make it extremely challenging to know how much of observed ridership growth post BRT implementation is attributable to the BRT presence versus improvements in service traits
The challenge of disentangling the cause-andeffect factors associated with ridership is exemplified in the case of the Cleveland HealthLine. This high-end BRT system, with perhaps the most comprehensive before-and-after analysis, reported the following ridership analysis results: "Total ridership within the corridor grew by $31 \%$ when comparing the before-and-after milestones. Ridership on the HealthLine itself increased by $60 \%$ and on the E-line by $20 \%$ over the time period. The remaining overlapping routes all lost ridership, with losses ranging from $2 \%$ to $23 \%$ as noted in Table 7. Whether you consider the $31 \%$ ridership growth of the corridor, or the $60 \%$ ridership growth of the HealthLine, both are substantial given the $30 \%$ decline in other bus ridership, and $22 \%$ decline in system wide ridership that occurred within the before and after period. The design of the BRT system with increased frequency and reduced travel time has contributed to the increased ridership." 2 already captured in modeling versus context condition changes that naturally occur over time (fare prices, economic conditions, gas prices, etc.). In the absence of a sufficient sample of this robust type of data that would enable statistical calibration, the adjustment process relies on a judgment-based method as an initial basis for BRT technology ridership adjustment factors.

The referenced GAO study includes analysis of ridership changes for sampled BRT systems. These results, shown in Figure 12, reflect total BRT route ridership changes without

${ }^{2}$ Cleveland State University, "Greater Cleveland Regional Transit Authority, Euclid Corridor Transportation Project: Bus Rapid Transit Before and After Study," working paper, Fall 2012.

3 Bus Rapid Transit Projects Improve Transit Service and Can Contribute to Economic Development," GAO-12-811, July 2012. 
adjustments to reflect redistribution of ridership in the corridor or ridership changes attributable to other factors already captured within the modeling framework. Researchers and stakeholders attribute a significant share of the ridership improvements of BRT to result from the travel time savings occurred by BRT investments. The service speed changes for select BRT's are shown in Figure 13. Even these data can be misleading, as BRT systems, depending upon how they were designed, occasionally introduce additional transferring in a passenger's total trip. The Franklin EmX in Eugene, Oregon, for example, required additional transferring which can impact the perceived total trip travel time independent of the BRT running time changes. ${ }^{4}$

Figure 12 GAO Data on BRT Ridership

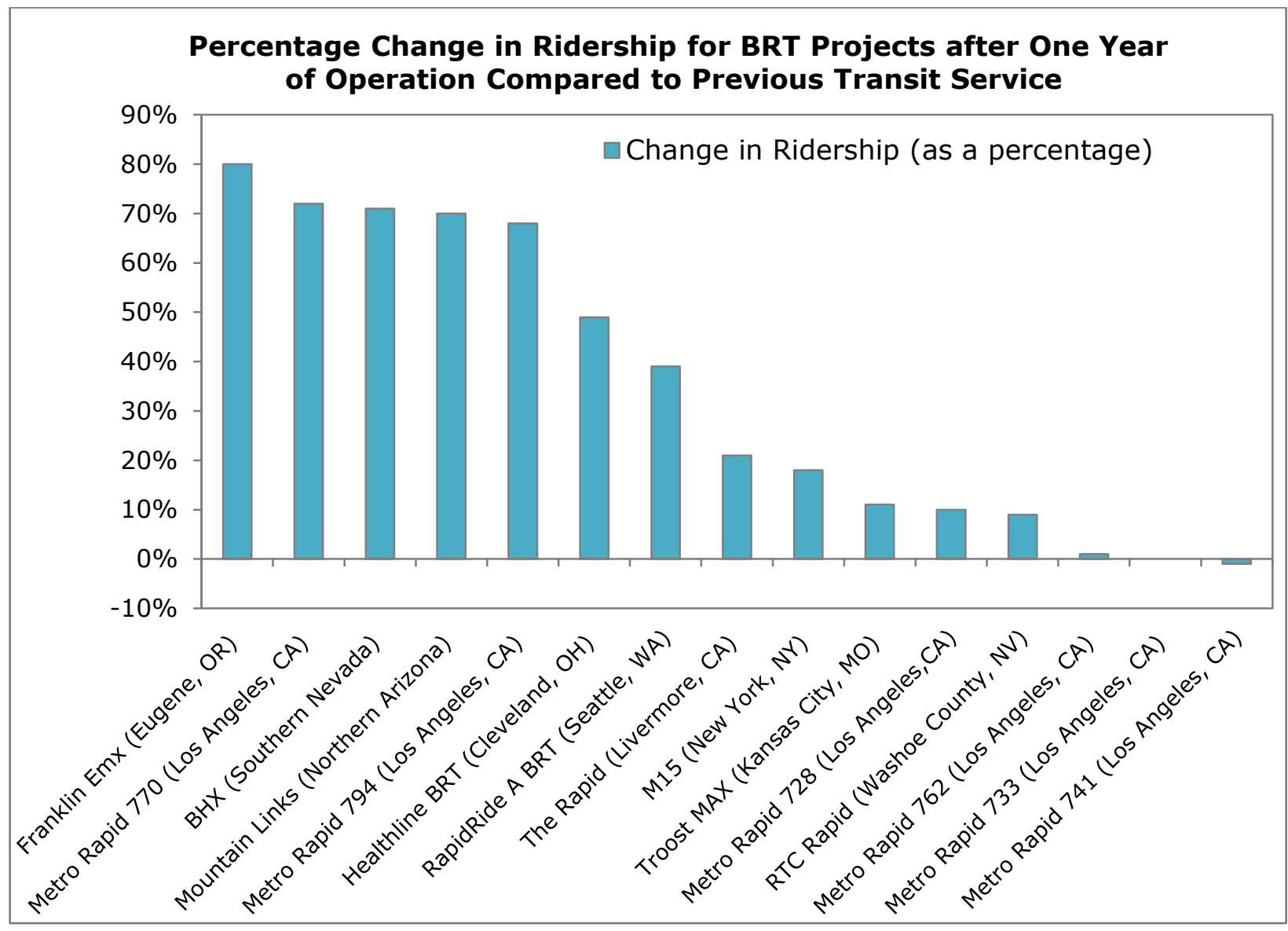

Source: "Bus Rapid Transit Projects Improve Transit Service and Can Contribute to Economic Development," GAO12-811, July 2012.

4 Thole, C., A. Cain, and J. Flynn, "The EmX Franklin Corridor BRT Project Evaluation," FTA-FL-267109.2009.2, Final Report, April 2009. 
Figure 13 GAO Data on BRT Speed Changes

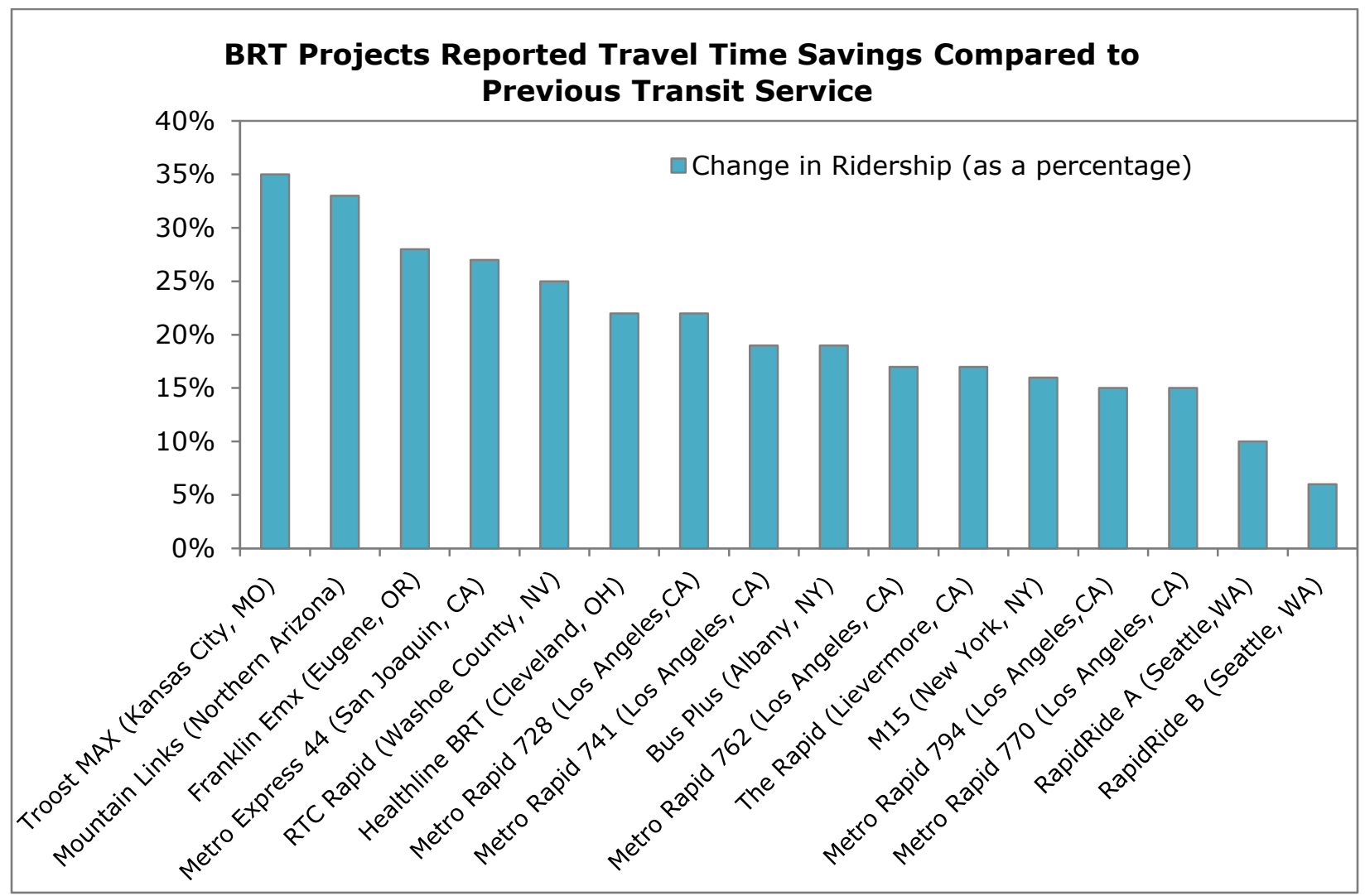

Source: "Bus Rapid Transit Projects Improve Transit Service and Can Contribute to Economic Development," GAO12-811, July 2012.

The next significant service factor can be characterized as service supply, a combination of the frequency of service and the span or hours of operation. Improvements in frequency and span of service have the effect of offering lower waiting times and/or greater opportunities to use the service. In many, but not all, cases, BRT offers improved service, often both better frequency and expanded hours of operation. However, conversion to articulated vehicles with their higher capacity might result in deterioration in service frequency for high-volume routes, as the larger vehicles could accommodate the demand with less frequent trips. Again, these service improvements are captured in TBEST and other travel demand modeling via existing coefficients that estimate demand based on service frequencies and speeds or accessibility (which is affected by speed).

With perfect data, one might use the percent increase in ridership (for example, the data in Figure 12) to determine what share of that increase in ridership can be explained by improved travel speed (Figure 13) and what share can be explained by changes in frequency and span of service, then attribute the remainder to the BRT technology. In comparing percent changes for specific projects between Figures 12 and 13, it can be seen that there is not necessarily any consistency in the relative magnitude of changes. This suggests that there is significant variance in the effects of BRT implementation across contexts beyond what can be explained by known changes in service characteristics (at least as captured by the available data). 
Interestingly, different sources report very different post-BRT implementation ridership data, perhaps depending upon the reference timeframe or the extent to which the focus was exclusively on the branded route versus net ridership changes within the corridor. Some relatively high-profile BRT projects, such as the LA Metro rapid corridors and the Kansas City Max system, show meaningful travel time savings but modest ridership impacts. Even similar systems, such as the Kansas City Max Main Street line versus the Kansas City Max Troost Street line, show very different results, with the Main Street Max reporting ridership increases of 29-50 percent and the Troost Max showing only single-digit ridership increases in the GAO report.

Effects of transit system characteristics on ridership as described in "Traveler Response to Transportation System Changes" (TCRP Report 95) were synthesized with a review of BRT studies to guide apportionment of observed BRT ridership increases between transit variables already known to impact ridership, such as travel speed and service supply, and others not currently accounted for. Based on this review, as well as focusing on relatively highly prescribed BRT systems such as those for which the maximum technology factor adjustments would be received (Kansas City Max line, Eugene, Oregon EmX line, and Cleveland HealthLine were systems with the most information available and all feature a highly-specified BRT system) and accounting to the extent possible for impacts of service and speed, a highly-prescribed BRT system resulted, producing approximately 25 to 30 percent greater ridership than would be the case for identical service having none of the BRT characteristics. Accordingly, the TBEST model BRT adjustment factor will use the scaling approach referenced above and provide a maximum 30 percent ridership adjustment associated with a perfect score of BRT features deployed throughout the BRT line.

It should be recognized that the vast majority of BRT proposals would involve implementation of only some BRT features and/or deploy only those features for part of the system. Most BRT proposals will include only selected BRT features and deploy those features unequally. Therefore, the maximum possible score will be rare. For example, the BRT score for the proposed HART MetroRapid system is 20 percent. This suggests that the impact on ridership of the HART BRT, excluding consideration of expanded service and faster running times, would be 20 percent; on the 30 percent scale discussed above, this would predict a 6 percent increase in overall transit ridership. Depending on the extent of service expansion and speed improvement, anticipated gain in ridership might be several times as large.

The suggested initial 30 percent ridership adjustment for highly-specified BRTs is a number that can be reviewed and updated over time as new data are obtained regarding the performance of BRT systems being deployed across the country. Numerous systems are currently in development and should provide many additional references for garnering a richer understanding of BRT specification impacts on transit ridership.

In reviewing existing documentation of BRT systems, the most glaring error in terms of trying to understand the full range of possible factors influencing ridership is the lack of a clear understanding of the change in service quantity in the BRT corridor. In many cases, BRT projects will impact numerous routes within the corridor, and impact assessments 
should attempt to capture an accurate measure of the change in service supply within the corridor. This increase in supply is likely to be a combination of improved frequency, expanded hours of operation, and, in some cases, additional route coverage.

Expanded data on BRT implementation will also provide additional insight into the variance of ridership response across different projects. With sufficient data, a fuller understanding of the extent to which socio-demographic characteristics or pre-existing service-level/ productivity might suggest different responses to BRT in different urban contexts. It will also be interesting to observe how ridership trends on BRT systems mature over time. Some of the data currently available show different percent ridership increases for the same system, perhaps based on different temporal reference points. In addition, some of the systems have been extended or modified and most probably have had their service adjusted based on operating experience during the first several months.

The transit industry generally expects transit route ridership to mature in an approximately two-year period of time as awareness increases and travel habits adjust to reflect the presence of the service. Initial customer acceptance of BRT might be accelerated due to the higher visibility of the infrastructure and service and the enhanced promotional initiatives and media attention likely to surround BRT implementation. Thus, the traditional phase-in period might be accelerated. It is unknown if there is any novelty effect associated with BRT implementation that might influence ridership initially but diminish over time or as more BRT systems are implemented.

The next section describes how the BRT capability is integrated into the TBEST model. 


\section{TBEST BRT Route Type Implementation}

Within the framework of this research, TBEST 4.1 has been updated to allow users to distinctively define BRT route characteristics by route and apply these characteristics within the TBEST modeling framework. To further emphasize BRT within TBEST, map visualization tools were developed to view BRT routes in relation to other route types within the system.

The procedures to apply BRT characteristic scoring to TBEST routes were derived from the methodology defined previously. To incorporate the procedures into TBEST required updates to the TBEST data schema, user interface, and code modules. BRT implementation testing was performed using the HART system and, specifically, the proposed MetroRapid BRT line.

\section{Schema Updates}

To accommodate route-level BRT characteristic scoring, the TBEST data schema was updated with three new tables. The BRT_ALLOCATION, BRT_ROUTESCORES, and BRT_CATEGORIES tables include data storage for BRT characteristic definitions, factor allocation, and user scoring. The table definitions are illustrated in Figure 14.

Figure 14 TBEST BRT Database Schema

BRT_ALLOCATION

BRT_ROUTESCORES

\begin{tabular}{|l|l|}
\hline \multicolumn{1}{|c|}{ Column Name } & \multicolumn{1}{c|}{ Data Type } \\
\hline allocation_id & smallint \\
\hline allocation_name & varchar(50) \\
\hline cat_id & smallint \\
\hline IA_allocation & smallint \\
\hline PP_allocation & smallint \\
\hline CS_allocation & smallint \\
\hline
\end{tabular}

\begin{tabular}{|l|l|}
\hline \multicolumn{1}{|c|}{ Column Name } & \multicolumn{1}{c|}{ Data Type } \\
\hline scen_id & smallint \\
\hline route_group_id & smallint \\
\hline allocation_id & smallint \\
\hline user_score & smallint \\
\hline
\end{tabular}

\section{BRT_CATEGORIES}

\begin{tabular}{|l|l|}
\hline \multicolumn{1}{|c|}{ Column Name } & \multicolumn{1}{c|}{ Data Type } \\
\hline cat_id & smallint \\
\hline cat_name & varchar(50) \\
\hline cat_factor & smallint \\
\hline
\end{tabular}

Data schema updates are deployed to individual TBEST users via a schema update library within the TBEST code. The library was updated to create and populate the new tables, create database views, and modify default domain values.

In addition to these updates, in prior versions of TBEST, BRT was defined as a Technology. To accommodate BRT as a Route Type, the BRT Technology code was removed from the 
TECHNOLOGY domain table and BRT was added to the TBEST ROUTE_TYPES domain table. This modification will be deployed to existing systems via the schema update library.

The map visualization required modifications to the Stops and Routes feature layers for each scenario. The schema update library was updated with schema updates that propagate route-level Route Type and Technology designations from the system SQL Server database to the GIS feature layers. This enables the TBEST map to display distinctive color patterns, line widths, and stops marker sizes per route type and technology type.

\section{BRT Route Definition and Characteristic Scoring}

Implementing the BRT route adjustment methodology required modification of the TBEST user interface to allow users to enter BRT characteristics and apply the characteristic scoring in the TBEST model stream. When defining a BRT route within TBEST, the method for developing route alignments, station locations, and service levels remains the same as for Bus or any other route type. Within a TBEST scenario, users can create a new route and define the type as BRT, or they can redefine an existing non-BRT route to BRT.

Specific BRT route characteristics are defined by accessing the BRT Route Characteristics Definition Form, as shown in Figure 1 earlier in this report. Within this form, users define the level of implementation of each characteristic by entering a score between 0 and 5 . The scoring entries are processed through the BRT score weighting system implemented within the TBEST source code. TBEST calculates the level of influence that each score has upon the route Image, Physical Presence, and Customer Service and displays the scoring results within individual gauges in the lower half of the form. The route-level adjustment to be applied is also calculated and displayed within the Route Adjustment gauge. Route scoring is stored within the database and can be modified at any time.

\section{BRT Route Map Visualization}

To support BRT map definition and visualization, TBEST was updated with functionality to provide distinctive map rendering by Route Type and Technology. The new Render Routes panel, as shown in Figure 15, allows users to define route color, line widths, stop sizes, and visibility by Route type and Technology. The Render Routes panel contains three environment settings:

1) Default Route Display and Editing

2) Route Type Render

3) Technology Type Render

The Default Route Display and Editing environment will be enabled by default but can be changed at any time by selecting another option within the Environment drop-down box. When the Render Environment is changed, the TBEST map updates to display the defined color and size settings. The settings can be modified by the user to emphasize certain render attributes or to toggle attribute visibility. Modified settings can be saved for future rendering within the transit system. 
Figure 15 TBEST Render Route Panel

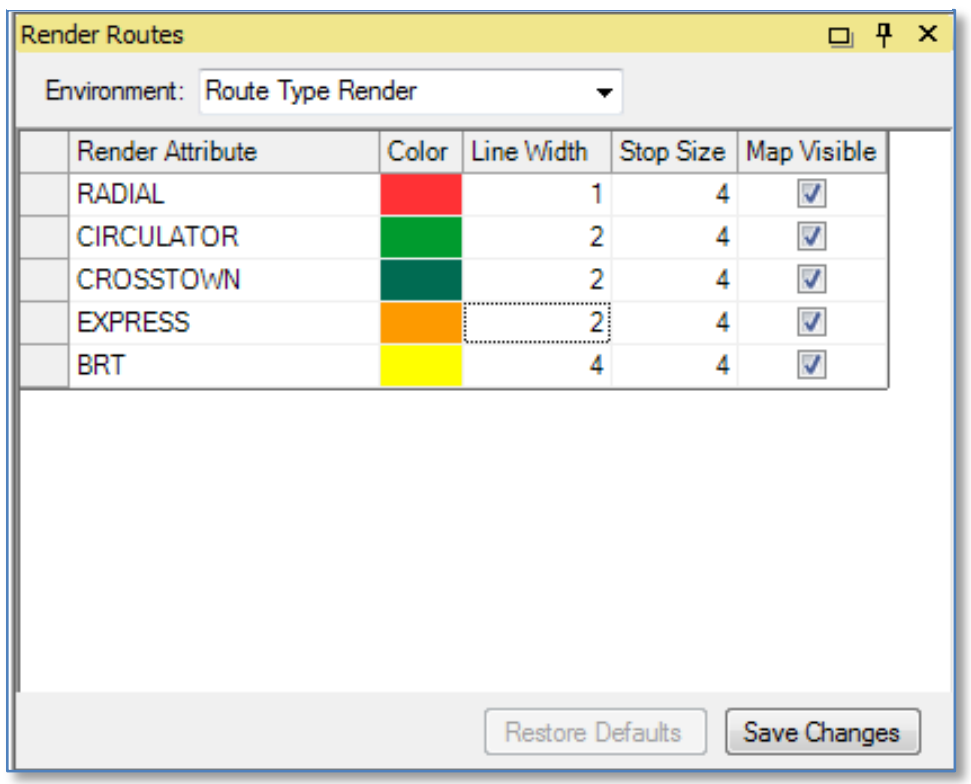

The TBEST map defined in Figure 16 illustrates map rendering of the options defined in Figure 15. Within this map of the HART transit system, BRT routes are displayed in yellow with a line width of 4 .

Figure 16 TBEST BRT Route Rendering

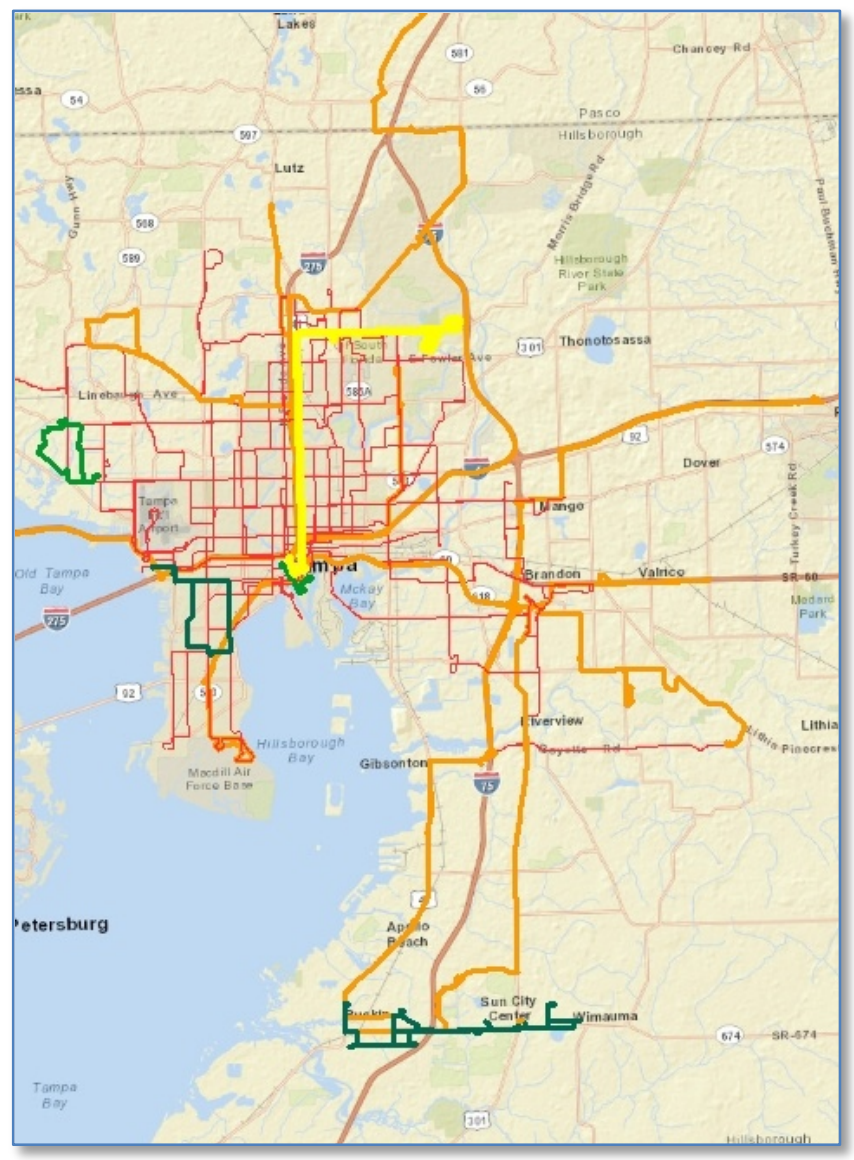




\section{BRT Implementation Testing}

The TBEST BRT ridership estimation process was tested using the proposed HART MetroRapid line. The MetroRapid BRT route amenities include bus preferential treatments (traffic signal priority, off-vehicle ticket vending machines), enhanced passenger stations, and special low-floor buses. The line has also been marketed by HART through the media and branding. The proposed MetroRapid BRT consists of two alignments: the North-South alignment serving Downtown Tampa to USF with extended service to the Hidden River area and the East-West alignment with service from Temple Terrace to Tampa International Airport.

The HART TBEST model was validated to the year 2011. Individual scenarios were created to code the MetroRapid EW and NS lines independently. To rate the implementation of BRT characteristics on the line, route characteristics where scored on a scale of 0 to 5 , with 0 equal to bus characteristics and 5 representing a highly-distinct BRT characteristic. The MetroRapid BRT characteristic scoring was entered into TBEST using the scores illustrated in Figure 17.

Figure 17 HART MetroRapid BRT Route Characteristics Definition

\begin{tabular}{|c|c|}
\hline Category & User Score \\
\hline Floor height & 0 \\
\hline Articulated & 0 \\
\hline Aerodynamic/aesthetic & 1 \\
\hline Alternative fuel & 0 \\
\hline Guided/steering technology & 0 \\
\hline \multicolumn{2}{|l|}{ Stations } \\
\hline Physical presence/architecture & 3 \\
\hline Shelter & 3 \\
\hline Real-time information & 1 \\
\hline Fare vending & 2 \\
\hline Off-vehicle fare collection & 0 \\
\hline \multicolumn{2}{|l|}{ Travel Way } \\
\hline Exclusiveness & 0 \\
\hline Signal preemption/priority & 1 \\
\hline Visual distinctiveness & 1 \\
\hline \multicolumn{2}{|l|}{ Branding/Marketing } \\
\hline Branding/marketing & 2 \\
\hline
\end{tabular}


Based on the user scoring defined in Figures 10 and 17, the route adjustment factor for MetroRapid was calculated to be 20 percent.

With the user scoring defined and route adjustment calculated, TBEST model runs were executed for all time periods (am peak, midday, pm peak, evening, Saturday and Sunday) with no other modifications to the system. As expected, when compared with a scenario containing the MetroRapid routes with no BRT characteristic definition adjustments, the forecasted MetroRapid ridership on both the EW and NS lines increased by 20 percent times the 30 percent Optimal BRT factor to produce a net result of a 6 percent ridership increase. 


\section{TBEST Model Validation with BRT}

TBEST uses the ridership estimation results compared with observed ridership to generate validation adjustment factors. Prior to validation, a model containing a BRT route(s) will have had user-defined route characteristic adjustments applied during the required prevalidation model run. Therefore, the TBEST model validation adjustment factors include any BRT adjustments entered by the user.

If a BRT route exists in the base year scenario, TBEST will apply any defined BRT characteristic adjustments as part of the validation. For example, the validation adjustment factor $(a V)$ is calculated for BRT Route A, which contains the level of BRT characteristic user-scoring to produce a 24 percent adjustment $(a B)$ to the base TBEST prediction $(n)$, which is 500 weekday riders. Within the model validation, BRT Route A has an observed ridership number $(s)$ of 680 . When the model validation procedure is run, TBEST will adjust the base TBEST prediction by 24 percent and then calculate the validation adjustment factor $(\mathrm{aV})$ as a factor of the 680 observed riders. In this case, the calculation for the model validation adjustment factor would be:

$$
a V=s /(n+(n \times(a B / 100))) .
$$

The calculation using the above example would be:

$$
680 /(500+(500 \times(24 / 100)))=1.34 .
$$




\section{TBEST Model Application with BRT}

Modeling BRT characteristics within TBEST can produce varied output, depending on the both the validation state of the model and the presence of existing BRT lines within the system.

1. Un-validated model - TBEST will apply BRT characteristic adjustment factor to unadjusted ridership estimation.

2. Validated model with no BRT routes in the base year - New BRT routes will accept two route adjustments: the validation adjustment applied to all new routes based on route type, technology, and time period and the BRT characteristic adjustment factor.

3. Validated model with BRT routes in the base year - For new BRT routes, TBEST will use BRT route type factors developed from the observed BRT ridership and the BRT characteristic adjustment factor. For modifications to characteristic definitions on existing validated BRT routes, TBEST will apply the modified BRT adjustment factor with the validation adjustment factor, which enables the model to retain the sensitivity to future-year BRT modifications on existing BRT routes.

When a route is designated as a BRT type, the user is able to access the BRT Route Characteristics dialog. Within this dialog, users enter a 0-5 rating based on the level of implementation of each characteristic. The scoring entries are processed through the weighting system to determine the adjustment factor to be applied to the route ridership forecast. The adjustment percentage is displayed for the user interactively as the scores are entered for each characteristic. The scores can be modified at any time.

\section{Model Stream}

The calculated BRT adjustment factor for the proposed route is applied to the route estimation during the model run. If desired, a TBEST model run option allows users to switch off the BRT factor during the model run.

The analyst operating the model will specify characteristics of the BRT corridor/facilities, which will result in adjustment factors to ridership calculated based on traditional service and accessibility features. The magnitude of this adjustment is based on a combination of modular judgment and industry experience in various applications.

The key appeal of the strategy is it allows sensitivity to the range of features within BRT initiatives and enables an area with no existing BRT service on which to calibrate forecasts to have a reasoned basis for initial estimates. 


\section{The LRT Strategy}

In many ways, the challenges of expanding TBEST to have an LRT forecasting capability is similar to the situation for BRT, as described previously. LRT is a decades-old technology but still suffers from modest data availability on deployed systems due to the relatively limited number of LRT systems in the U.S. Regarding LRT forecasting, standard industry practice is to build local transit forecasting models with guideway sensitivity based on local calibration where possible (fewer than two dozen, depending on how streetcar and legacy systems are counted). In the absence of local systems, coefficients are borrowed or transferred from similar contexts where available. There is also a high degree of variance regarding LRT specifications in terms of performance characteristics and even in terms of physical presence. As was the case with BRT, there are no LRT systems operating in Florida.

The nature of forecasting for LRT is somewhat different than for bus services in that these are much more significant capital investments and, hence, there is more extensive planning and demand analysis as a part of the planning process. Typically, the planning and environmental processes that precede LRT investment include extensive demand forecasting/modeling work at the local level. Also, the nature of LRT planning has typically had a longer timeframe of analysis, with a design year (forecast year) 20-30 years in the future, which requires the development of various model inputs reflecting anticipated conditions in that future year. TBEST is generally targeted for a 5- to 10-year forecasting horizon. LRT systems, with both high capacity and significant capital cost, are more likely to be coordinated in conjunction with other roadway capacity improvements and land development scenarios. Thus, TBEST LRT forecasting is more likely to be for the purpose of planning bus network integration with an LRT project or for the purposes of conducting sketch planning of possible LRT projects that might have more detailed integrated multimodal modeling as the project moves through the planning process. Thus, TBEST is unlikely to be the definitive source of LRT forecasts for purposes of complying with FTA demand forecasting.

In light of the absence of actual Florida experience for calibration, a variety of other possible strategies for determining a model/adjustment process that realistically represents LRT in TBEST were explored. Without Florida LRT ridership data, the project team speculated on the possibility of using other documented LRT forecasting methods to produce an LRT forecast that could then be used as "actual" ridership for purposes of subsequent TBEST LRT calibration. While somewhat unorthodox, this method has the virtue of enabling the production of an LRT forecast that uses validated composite behaviors regarding LRT drawn from a host of LRT applications.

More specifically, four different LRT sketch planning type tools were considered as a basis for defining LRT ridership for purposes of calibration to TBEST. The options are to fit the TBEST LRT model to:

- Existing FTA LRT sketch planning tool.

- Regional model forecasts. 
- Sketch planning tool developed as part of TCRP Project H-42, "An Exploration of Fixed Guideway Transit Criteria Revisited."

- New FTA sketch planning tool model known as STOPS (Simplified Trips-on-Project Software), expected to be available when the final New Starts and Small Starts Policy Guidance is available later in 2013.

Due to schedule constraints and with the concurrence of FDOT, Options 3 and 4 were eliminated because they were not publicly available for application at the time of this publication. Option 2, using regional model forecasts as "actual" ridership to which TBEST would be calibrated, was a possibility; however, forecasts that reflect current transit service and conditions are not available for the recommended application site in Florida (Hillsborough County) nor for other Florida locations. Thus, the existing FTA sketch planning tool was used to develop a ridership forecast for the LRT/BRT corridor in Hillsborough County.

This model, known as the Aggregate Rail Ridership Forecasting (ARFF) Model 2.0, operates using Census Transportation Planning Package (CTPP) commuting flow data as a foundation and demographic database. The model was developed by AECOM Consultants for FTA in 2009. This spreadsheet-based tool and its documentation are available from FTA. As a sketch planning tool, the model is relatively easy to use but produces only line-level ridership forecasts (as opposed to stop-level forecasts). One of the appeals of employing the strategy of using the ARRF model is the fact that it was developed based on data from a variety of North American LRT experiences and, hence, reflects a composite set of conditions characteristic of domestic LRT markets and systems. Screen captures of the spreadsheet model are shown in Figure 18. 
Figure 18 Screen Capture of ARRF Spreadsheet of HART BRT Route ARRF II v1 (Combined LRT/CR Model)

Project: $\quad$ MetroRapid

Alternative: North South Alignment

Date: $\quad 11 / 1 / 2012$

\section{Input Data}

1. System Operational Characteristics
1a. Directional Route Miles
1b. Weekday Train Revenue Miles
1c. Weekday Train Revenue Hours
1d. Average Speed in MPH (if blank, computed from $1 \mathrm{~b}$ and 1c)
1e. Trains per day per direction (if blank computed from $1 \mathrm{a}$ and $1 \mathrm{~b}$ )

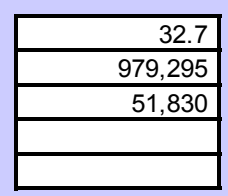

2. CTPP Flows

2a. Home within 2 miles of any station and Work within 1 mile of any station 2.a.i Employment $<50,000$ / square mile

2.a.ii Employment $>50,000$ / square mile

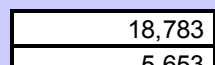

2b. Home within 6 miles of a PNR station and Work within 1 mile of any station 2.b.i Employment $<50,000$ / square mile

2.b.li Employment $>50,000$ / square mile

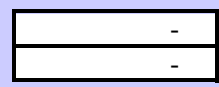

3. Suburban-CBD Service flag

3a. Code 1 if service is designed for connecting suburban areas to CBD otherwise, code 0

\section{Parameters}

1. Elasticity Base Speed

2. Demand elasticity with respect to speed

0.400

3. Normalization Factor on Speed Adjustment

0.978

4. Minimum Speed to Adjust

5. Maximum Speed to Adjust

6. Elasticity Base Average Trains/Day (per direction)
7. Demand elasticity with respect to Trains/Day

1.000

$1,000.000$

58.436

8. Normalization Factor of Trains/Day

0.490

0.826

1.000

9. Minimum Trains/Day to Adjustment

10. Maximum Trains/Day to Adjustment

$1,000.000$

52.000

0.550

12. Work Trip Train Frequency Adjustment for Infrequent Trains - Adjustment

140.000

13. Non-Work Trip Adjustment for Long Corridors - Dir. Rte Miles at mid-point of adj.

14. Non-Work Trip Adjustment of Long Corridors - Coefficient (slope) on adjustment

0.050

0.550

0.680

16. Adjustment for predominantly suburban/CBD service

17. Unlinked Walk/Bus/KNR Access to Work Trips/CTPP Flow $-<50,000 /$ square mile

0.109

0.149

18. Unlinked Walk/Bus/KNR Access to Work Trips/CTPP Flow - $>50,000 /$ square mile

0.031

0.128

20. Unlinked PNR Access to Work Trips/CTPP Flow $>50,000 /$ square mil

0.205

0.158

21. Unlinked Walk/Bus/KNR Access to Non-Work Trips/CTPP Flow $-<50,000$ / square

0.017

23. Unlinked PNR Access to Non-Work Trips/CTPP Flow $-<50,000 /$ square mile

0.036 
Figure 18 (continued) Screen Capture of ARRF Spreadsheet of HART BRT Route Level-of-Service Service Factor

Average Speed (Item 1d if coded, otherwise 1b/1c)

Maximum Normalized Speed Adjustment

Computed Speed Adjustment

Normalized Speed Adjustment

Bounded Speed Adjustment

Trains Per Day (Item 1e if coded, otherwise 1b/1a)

Minimum Normalized Trains Per Day Adjustment

Maximum Normalized Trains per Day Adjustment

Adjustment for Trains Per Day

Normalized Trains Per Day Adjustment

Bounded Trains Per Day Adjustment

Total Level-of-Service Factor

\section{Other Adjustments}

Infrequent Trains per Day Max Elasticity

Work Trip Train Frequency Adjustment for Infrequent Service

Non-Work Demand Adjustment for Long Corridors

Adjustment for Non-CBD Trips for suburban-CBD-oriented Services
1.1413

1.0000

0.9979

0.6800

Rail Unlinked Trips

Daily Work Walk/Bus/KNR Access unlinked trips to employment $<50,000 /$ sq mile

Daily Work Walk/Bus/KNR Access unlinked trips to employment $>50,000 / \mathrm{sq}$ mile

Daily Work PNR Access unlinked trips to employment $<50,000 /$ sq mile

Daily Work PNR Access unlinked trips to employment $>50,000 /$ sq mile

Subtotal Work Daily unlinked trips

Daily Non-Work Walk/Bus/KNR Access unlinked trips to employment $<50,000 /$ sq mile Daily Non-Work Walk/Bus/KNR Access unlinked trips to employment $>50,000 / \mathrm{sq}$ mile Daily Non-Work PNR Access unlinked trips to employment $<50,000 /$ sq mile Daily Non-Work PNR Access unlinked trips to employment $>50,000 /$ sq mile Subtotal Non-Work Daily unlinked trips

Total Daily unlinked trips

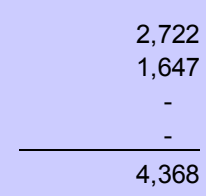

5,105

1,742

6,846

11,215

Ridership results using this model were calculated for two legs of the BRT corridor project known as MetroRapid currently being implemented in Tampa. As shown in Table 2, the adjustment factors necessary to convert TBEST numbers to replicate ARRF forecasts are both large and very significantly different between the two alignments.

Based on these results, the results were compared to the ridership forecasts carried out as part of the Hillsborough County Alternative Analysis for the North-South corridor in Hillsborough County. These forecasts also suggested an approximate doubling of ridership for the rail alignments compared to similar levels of bus service.

The project team found the variation beyond the range of credibility of technology adjustment factors observed in travel forecasting. In light of these variances, the project team reflected on the potential reasons for the variation, concluding that part of the variation is a result of the timeframes for forecasting where LRT forecasts are typically for a $20+$ year time horizon and may be operating in a situation where the relative competitive 
comparison of travel preference between roadway and transit travel has changed. Typically, LRT systems have significant park-and-ride components of ridership that are not currently well-handled within the TBEST framework. In addition, LRT systems typically result in rather dramatic reconfiguration of bus services within a broadly-defined corridor of implementation, with the intention of directing a great deal of the overall system demand on to the LRT alignment. In the test application case, several parallel high-performing bus routes continue to exist in the TBEST simulation. In reality, more dramatic service reconfiguration might be anticipated with LRT implementation and would serve to boost ridership on the LRT alignment.

In light of these findings, it is recommended that the LRT adjustment factor be set no greater than 50 percent and be redesignated after the completion of the FTA STOPS model. The modified TBEST framework and the incorporation of an adjustment factor for LRTs within that framework will enable these changes to be made quite expeditiously.

Additionally, further testing, perhaps against LRT proposals in Florida, such as those in Pinellas and Broward counties, might provide additional opportunities to explore TBEST LRT forecasting capabilities with more robust feeder service specification and the availability of regional model ridership forecast results. 
Table 2 TBEST LRT Calibration via TBEST Bus/ARRF Comparisons

\begin{tabular}{|c|c|c|c|c|c|c|c|c|c|c|}
\hline $\begin{array}{l}\text { Route - Metro Rapid North } \\
\text { South Line (No CBD Flag) }\end{array}$ & $\begin{array}{c}\text { Total Daily } \\
\text { Unlinked } \\
\text { Trips }\end{array}$ & TBEST & Estimates & by Time Pe & riod & $\begin{array}{c}\text { TBEST } \\
\text { Population }\end{array}$ & $\begin{array}{c}\text { TBEST } \\
\text { Employment }\end{array}$ & $\begin{array}{c}\text { \# of Stations } \\
\text { per } \\
\text { Direction }\end{array}$ & $\begin{array}{l}\text { Weekday } \\
\text { Headway }\end{array}$ & $\begin{array}{l}\text { Weekday } \\
\text { Service Span }\end{array}$ \\
\hline & & AM Peak & Off Peak & PM Peak & Night & & & & & \\
\hline Route 2 & 3877 & & & & & 7402 & 8909 & 75 & 15 & 20 \\
\hline ARRF Model* & 14898 & & & & & & & 31 & 15 & \\
\hline TBEST Weekday Model & 7541 & 1487 & 2454 & 1713 & 1643 & 5622 & 13069 & 31 & 15 & 20.5 \\
\hline Adjustment Factor & 1.98 & & & & & & & & & \\
\hline
\end{tabular}

\begin{tabular}{|l|c|c|c|c|c|c|c|c|c|c|}
\hline Route - Metro Rapid East West Line & \multicolumn{2}{|c|}{ TBEST Estimates by Time Period } & BEST Populati & EST Employmeations per Di & Headway & Service Span \\
\hline & & AM Peak & Off Peak & PM Peak & Night & & & & & \\
\hline ARRF Model & 10479 & & & & & & & 21 & 15 & \\
\hline TBEST Weekday Model & 2694 & 546 & 947 & 525 & 676 & 3178 & 11178 & 21 & 15 & 20.5 \\
\hline \multicolumn{1}{|c|}{ Adjustment Factor } & $\mathbf{3 . 8 9}$ & & & & & & & & & \\
\hline
\end{tabular}

* The North South Line Unlinked trips were calculated with the ARRF CBD flag off. With the CBD flag on, the unlinked trips are calculated to be 11,215 


\section{Light Rail Network Coding}

Light Rail routes can be defined in TBEST using existing network coding tools. When creating a Light Rail route, users will define the Technology as Light Rail; the Route Type will generally be characterized as Radial or Crosstown. Figure 19 is an example of the New Route dialog within TBEST with the Technology defined as Light Rail.

Light Rail stations are coded using the same methods as the Bus technology except station spacing will generally be further apart, and coded light rail stops, which are further away from employment centers, will generally require a park-and-ride special generator designation. In addition, the planned coordination of Light Rail and Bus operations should be reflected in network updates. To induce more transferability with feeder routes, each LRT station and corresponding connecting stop on a feeder route should be coded with a Transfer Station identifier. The Transfer Station designation will decrease the model transfer penalty for switching routes within a trip and better reflect the synchronized arrivals of fixed guideway transit and supporting bus operations.

Figure 19 TBEST New Route Dialog for LRT Designation

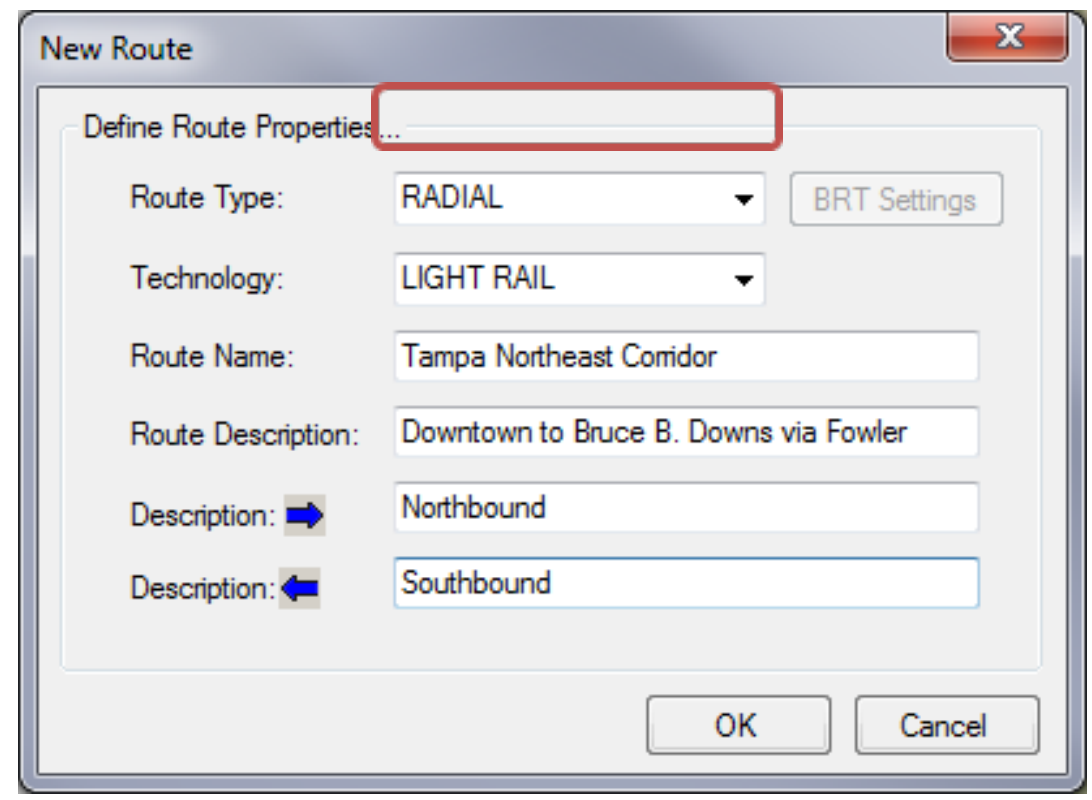

\section{TBEST Model Application with LRT}

The LRT ridership adjustment factor is the single factor applied to routes designated as LRT for any TBEST time period in which the route operates. For model application, the TBEST application of the LRT ridership adjustment factor is coordinated with model validation adjustment factors. The LRT adjustment is applied to the projected ridership at each stop along the LRT line. If the model is not validated, the LRT factor will be the only adjustment. 
If the model is validated, the product of the LRT adjustment factor and the validation adjustment factor are applied to the raw predicted ridership at each stop.

\section{Summary}

In general, available data provides a reasonable basis for the BRT forecasting methodology identified and implemented for treatment of BRT systems within the TBEST model framework. The TBEST model structure is such that, as additional experience with BRTs is documented, modifications to adjustment factors can be made as results suggest. The incorporation of a strategy for treating variously-specified BRTs embraces a great deal of judgment, not all of which has been borne out by empirical or experimental analysis but that is consistent with both travel behavior theory and anecdotal observations of BRT ridership impacts. Again, as more knowledge is gained regarding the importance of various BRT features, modifications to the weighting/factoring strategy may be appropriate.

With regard to the LRT treatment, additional research might be helpful to improve the confidence in LRT ridership adjustment factors. Stronger treatment of park-and-ride markets within TBEST might also be an appropriate prerequisite to further refinement of LRT forecasting capabilities in TBEST. Additional empirical data on stop-level LRT ridership might also help with calibration of LRT adjustments to TBEST. In any case, the level of effort in adapting TBEST to better accommodate LRT modeling needs to be weighed against the probability that areas pursuing LRT are also likely to be doing regional modeling, relegating the TBEST LRT features to serving the role of enabling TBEST to remain a realistic tool for bus service planning in urban environments that have LRT versus a tool specifically for LRT forecasting. 


\section{References}

Cleveland State University, "Greater Cleveland Regional Transit Authority, Euclid Corridor Transportation Project - Bus Rapid Transit Before and After Study," working paper, Fall 2012.

GAO, Report to the Committee on Banking, Housing, and Urban Affairs, U.S. Senate, "Bus Rapid Transit Projects Improve Transit Service and Can Contribute to Economic Development," GAO-12-811, July 2012.

Thole, C., A. Cain, and J. Flynn, "The EmX Franklin Corridor BRT Project Evaluation," FTAFL-26-7109.2009.2, Final Report, April 2009.

Transit Cooperative Research Program (TCRP), Bus Rapid Transit Practitioner's Guide, Washington, DC, 2007.

Transit Cooperative Research Program (TCRP), "Traveler Response to Transportation System Changes Chapter 9, Transit Scheduling and Frequency," TCRP Report 95, Transportation Research Board, Washington, DC, 2004.

Transit Cooperative Research Program (TCRP), "Traveler Response to Transportation System Changes Chapter 12, Transit Pricing and Fares," TCRP Report 95, Transportation Research Board, Washington, DC, 2004. 